Frontiers in Neuroendocrinology

Frontiers in Neuroendocrinology 29 (2008) 490-506

\author{
Review
}

\title{
Anabolic-androgenic steroid dependence? Insights from animals and humans
}

\author{
Ruth I. Wood* \\ Department of Cell \& Neurobiology, Keck School of Medicine of the University of Southern California, \\ 1333 San Pablo Street, BMT 401, Los Angeles, CA 90033, USA
}

Available online 3 January 2008

\begin{abstract}
Anabolic-androgenic steroids (AAS) are drugs of abuse. They are taken in large quantities by athletes and others to increase performance, with negative health consequences. As a result, in 1991 testosterone and related AAS were declared controlled substances. However, the relative abuse and dependence liability of AAS have not been fully characterized. In humans, it is difficult to separate the direct psychoactive effects of AAS from reinforcement due to their systemic anabolic effects. However, using conditioned place preference and self-administration, studies in animals have demonstrated that AAS are reinforcing in a context where athletic performance is irrelevant. Furthermore, AAS share brain sites of action and neurotransmitter systems in common with other drugs of abuse. In particular, recent evidence links AAS with opioids. In humans, AAS abuse is associated with prescription opioid use. In animals, AAS overdose produces symptoms resembling opioid overdose, and AAS modify the activity of the endogenous opioid system.
\end{abstract}

(C) 2008 Elsevier Inc. All rights reserved.

Keywords: Anabolic agents; Testosterone; Substance abuse; Self-administration; Hamsters; Reward; Drug dependence

\section{Breakfast of champions: recent history and prevalence of AAS use}

Anabolic-androgenic steroids (AAS) are a hot topic. A search of the Google news archive in March 2007 reveals 47,500 news stories on "steroids" in 2006, a $400 \%$ increase since their debut in the archive in 2002. In 2006, "steroids" even surpassed trend-setters such as "Paris Hilton" (38,500 stories) or "spinach" (42,700 stories). Current media attention on AAS abuse has been driven by accusations of steroid use among professional athletes in baseball, track, and cycling. However, public recognition of AAS use in sports dates back nearly 20 years, when Ben Johnson tested positive for stanozolol at the Seoul Olympics in 1988 [77]. Eastern Block athletes had been using steroids since the 1950s, and the International Olympic Committee banned steroid use from Olympic competition in 1976. However,

\footnotetext{
* Fax: +13234423466 .

E-mail address: riw@usc.edu
}

the ability to reliably detect androgen metabolites in urine samples was limited until the advent of gas chromatography-mass spectroscopy [89]. Johnson's drug test spurred the United States Congress to pass the Anabolic Steroid Control Act of 1991 which declared steroids as controlled substances. In 1999, the World Anti-Doping Agency (WADA) was founded to coordinate steroid control measures among national sporting federations.

Despite these bans, steroid use has moved from the province of elite athletes into high school athletic programs and neighborhood fitness centers. For teens and young adults, steroids represent a short-cut to a lean and muscular physique. For aging baby boomers, steroids help stave off age-related declines in muscle mass. Several national surveys have demonstrated widespread AAS use, especially among teens (Fig. 1). According to the 1994 National Household Survey on Drug Use, steroid use peaks in late adolescence at 18 years of age [148]. Moreover, in the 2002 Monitoring the Future survey [86], the lifetime incidence of steroid use among high school seniors $(4.0 \%)$ was comparable to that for crack cocaine $(3.8 \%)$ or heroin 

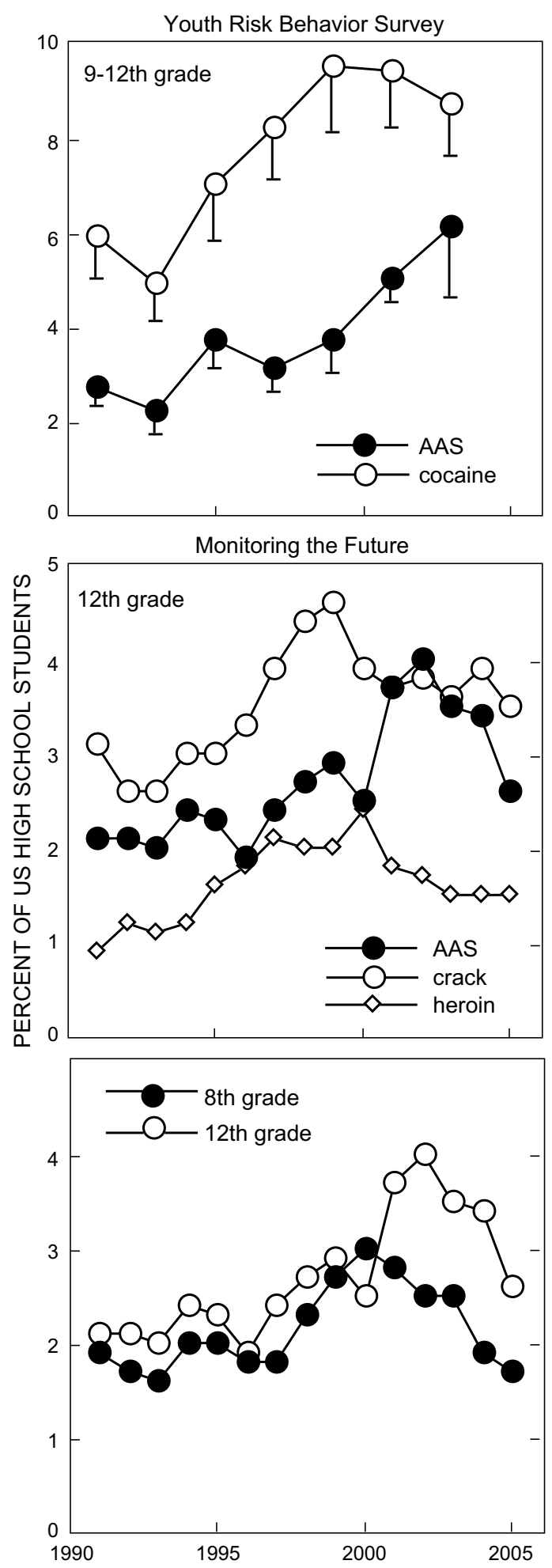

Fig. 1. National trends in teen steroid use from 1990 to 2005. Data on anabolic-androgenic steroid (AAS) use among high school students in the United States is collected as part of the Youth Risk Behavior Survey [57] (top panel) and the Monitoring the Future Study [86] (middle and lower panels). The percent of American high school students who have ever used AAS (closed symbols) is compared with the percent who have used cocaine, crack or heroin (open symbols). The bottom panel compares AAS use among 8th grade (closed symbols) and 12th grade (open symbols) students.
(1.7\%). Similarly, the Youth Risk Behavior Surveillance System survey found in 2005 that nearly $5 \%$ of high school boys had used AAS, compared with $3.3 \%$ reporting heroin use [57]. Steroid use is also increasingly common at younger ages: $2.5 \%$ of 8 th grade students (13-14 years) have used steroids, similar to the incidence of crack $(2.5 \%)$ and heroin use $(1.6 \%[86])$.

\section{What me worry? Risks and side effects of steroid use}

AAS are indeed performance-enhancing substances; there is no longer any question that they work. In the 1970 s and early ' 80 's, the medical/scientific community maintained that AAS did not significantly enhance strength or muscle mass. This conclusion was based on studies combining low-doses of androgens with exercise in sedentary volunteers (reviewed in [104]). Based on their own empirical evidence, elite athletes had already reached the opposite conclusion. Eventually, with properly controlled studies testing higher doses of androgens, the doctors and scientists agreed. According to the American College of Sports Medicine Position Stand: The Use of Anabolic-Androgenic Steroids in Sports, AAS "contribute to increases in body weight and lean body mass. The gains in muscular strength achieved through steroid use...improve performance and seem to increase aerobic power or capacity for muscular exercise" [1].

If AAS improve athletic performance, should they be restricted? Steroid use has been condemned on ethical grounds that AAS provide an unfair advantage and diminish the value of talent and training on athletic performance (reviewed in [30]). However, the pressure for athletic achievement and the attendant financial rewards have eclipsed the argument banning steroids to maintain a level playing field. Therefore, the key issue becomes: are steroids dangerous? From muscle magazines to YouTube videos $[65,71,165]$, steroid users defend their use of performanceenhancing substances as a "healthy lifestyle choice". Unlike the profile of a typical illicit drug user, many people who take steroids pay careful attention to diet and exercise to maximize muscle gains. Steroid users are often knowledgeable about the biochemistry of the substances they use, and they are well-connected via websites such as www.musclehead.com, www.anabolex.com, www.mesomorphosis.com and on blogs and chat rooms.

Nonetheless, most media promoting steroid use acknowledge the potential for adverse side effects. These include cosmetic changes (acne, baldness; gynecomastia and testicular atrophy in men; clitoromegaly, facial hair, and lowering of the voice in women), reversible infertility in both sexes, as well as more serious health consequences (stroke, liver failure, cardiac arrhythmia and infarction) $[25,26,39,61,92]$. Steroid use among younger teens also carries the risk of stunting final adult height due to premature closure of the epiphyseal plates [101]. At the same time, steroid advocates argue that side effects are minimal and steroids are safe if used properly $[65,71,165]$. This becomes an 
irrefutable argument: anyone who suffers an adverse event from steroids must have been using them improperly.

The real risks of steroids are a matter of debate. In an interview for the video Truth about steroids, John Romano, senior editor of the body-building magazine Muscular Development, asks "Where are the bodies?" A limited number of case studies have linked sudden cardiac death to illicit AAS use in young adults $[49,92,108,164]$. However, such acute cardiac events are rare. More likely, steroids may cause long-term changes in cardiovascular and hepatic function that are manifest only years later $[48,128]$. Under these circumstances, it is difficult to definitively identify AAS abuse as a contributing factor. However, a study of 62 elite Finnish powerlifters who used AAS during their competitive years reported a significantly increased death rate during the 12-year follow-up [127]. Premature deaths also occur in mice treated chronically with AAS [21]. Recent evidence suggests that steroid use is increasing [86], both in terms of the number of users, and the types and amounts of steroids used. As the current population of AAS users ages, it will be important to investigate this question in larger groups of subjects.

Psychiatric side effects due to AAS are another source of concern. Early studies in the late 1980s and early 1990s described mania and hypomania, violent behavior, suicide, anxiety and paranoia among individual steroid users $[23,24,75,122,136,137]$. Suicide and homicide account for a substantial fraction of the premature deaths among steroid users [174]. Several high-profile cases of teen suicide have highlighted the potential for depression during withdrawal from steroids (see http://www.taylorhooton.org). In addition, the increased aggression associated with AAS use ('roid' rage) may pose a risk to other people $[33,173]$. Steroid use has been implicated in several violent murders $[38,138,141,156]$. This does not mean that everyone who uses steroids will suffer crippling depression or homicidal rage. However, steroids appear to contribute to psychiatric dysfunction in susceptible individuals.

\section{Just say no: AAS reinforcement and dependence in humans}

There is also concern that dependence may develop with chronic steroid use. Kirk Brower has proposed a 2-stage model of steroid dependence [22]. The anabolic effects of AAS provide the initial motivation to take AAS. Nonetheless, with chronic use, physiologic and psychologic dependence may develop, thereby making it difficult for users to quit. Ten months before his death from brain cancer in 1992, former NFL defensive end Lyle Alzado discussed his steroid use in Sports Illustrated: "It was addicting, mentally addicting. I just didn't feel strong unless I was taking something" [4]. A number of investigators have suggested the potential for AAS dependence in human users $[22,23,25,27,34,70,93,106,167]$. Studies of AAS dependence have included surveys of current and former AAS users or prospective studies of AAS treatment in human volunteers.
Surveys of AAS users recruited from gyms, websites and physicians have yielded information on the types and doses of steroids used, and self-reported symptoms of dependence and withdrawal. In a survey of 8 AAS users, Brower et al. [27] reported numerous criteria for psychoactive substance dependence, including continued use despite negative side effects, and withdrawal symptoms when steroids were discontinued. Similarly, $57 \%$ of 49 active AAS users met DSM-II-R criteria for dependence [25]. Dependent users reported larger doses, more cycles of use, and greater dissatisfaction with body image. In other studies, elevated aggression and irritability were the most common behavioral side effects of AAS use $[18,66,113,126,130]$, although Moss et al. [115] concluded that AAS use enhanced sexual desire. In addition, Pope and Katz [139] and Bolding et al. [16] found higher levels of depression and suicidal thoughts among AAS users compared with non-users. Women who use AAS also exhibit signs of dependence [70].

Given the range of androgen exposures, the variety of psychiatric symptoms, and the potential for pre-existing psychiatric dysfunction, is difficult to determine the precise role of AAS in surveys of current users. Prospective studies of human volunteers receiving injections of AAS have generally reported fewer psychiatric side effects. In a study of normal men receiving testosterone at doses from 100 to $500 \mathrm{mg} /$ week, Yates et al. [188] found only one clinically significant psychological effect. Similarly, Tricker et al. [175], O'Connor et al. [121] and Fingerhood et al. [59] reported no increases in angry behavior [121,175] or subjective drug responses ("feel the drug", "feel high" [59]). However, other studies have observed increased aggression $[42,72,98,140,163]$, positive mood including sexual arousal and manic scores $[5,42,72,140,163]$, as well as changes in cognitive [42] and psychomotor function [72].

In surveys and prospective studies, increased aggression is the most consistent behavioral effect of high-dose AAS exposure. Accordingly, it seems to fair to conclude that AAS have the potential to enhance agonistic behavior in humans, as they do in animals [58,74]. However, aggression may not necessarily be the only behavioral consequence of AAS abuse. Rather, due to widespread media reports of inappropriate aggression ('roid' rage), aggression is the behavior most commonly measured. What about other psychiatric effects? Specifically, how do we reconcile the different results of user surveys and prospective studies? It is important to keep in mind that the doses administered to human volunteers (typically, up to $600 \mathrm{mg} /$ week) are much lower than the doses advocated on body-building websites (up to $2 \mathrm{~g} /$ week, as in "The California Mass Stack" [170]), and the duration of treatment is generally short in controlled clinical studies. Therein lies the catch: the steroid regimens in controlled studies may be inadequate to reveal significant psychiatric effects, but it would be unethical to test doses that we suspect are actually in use. On the other hand, it may be that the AAS users who agree to participate in surveys are more susceptible to the psychiatric side effects of AAS. 
This brings up the very real possibility of individual differences in susceptibility to AAS. It has been argued that "steroids are clearly not addictive in the same way that compounds such as cocaine or heroin are" [71]. Indeed, anecdotal information from human AAS users highlights the range of individual responses. That is, while some individuals appear to tolerate repeated steroid cycles, symptoms of steroid dependence develop in susceptible individuals (reviewed in [22]). However, this does not necessarily imply that steroids are benign, as argued in a highly critical review of our work published in the body-building magazine, Muscle Development [71]. Many people can drink, smoke and bet on horses occasionally without developing dependence, yet we recognize the addictive potential of alcohol, nicotine and gambling. AAS dependence may reflect the specific pattern of steroid use superimposed against a background of individual susceptibility.

\section{Betcha can't take just one: stacks and supplements}

Another thing to keep in mind is that most steroid users do not limit themselves to a single dose or a single type of steroid. Instead, human users commonly combine different steroids ("stacking") in cycles of increasing and decreasing concentrations ("pyramiding"). As an example, in the 5th week of the "California Mass Stack" [170], the user would take over $2 \mathrm{~g}$ of steroids, plus an aromatase inhibitor and an anti-estrogen. The idea behind stacking is to achieve a synergistic anabolic effect by combining compounds with contrasting properties (long vs short-acting, aromatizable vs reducible, oral vs injectable, [189]). Users aim to "activate more receptor sites" with androgen stacks [165]. In that only one genomic androgen receptor has been identified [67], the biochemical rationale for stacking seems weak at face value. However, considering that each AAS has a unique balance of androgenic, anabolic, estrogenic, anesthetic, and lipolytic effects, the empirical effectiveness of stacks should not be easily dismissed.

The argument for pyramiding is easier to appreciate. Pyramiding is used to avoid plateauing (developing tolerance to a particular steroid) and to minimize withdrawal symptoms when steroid use is suspended [165]. To maximize gains in muscle mass and athletic performance while minimizing side effects and conserving limited drug supplies, AAS users start with lower androgen doses which gradually build over a period of several weeks [189]. Eventually, the dose of androgen is decreased. This is particularly important for athletes subject to drug testing during competition. Gradually tapering the androgen dose avoids steroid withdrawal and helps the user maintain muscle gains [168].

Most stacks will include both androgens and non-steroidal drugs. The latter are designed to counteract negative side effects of AAS (aromatase inhibitors, estrogen receptor antagonists), to enhance fat and water loss (diuretics, thyroid hormones, $\beta 2$ adrenergic receptor agonists) and to reactivate endogenous steroid production at the end of a cycle (gonadotropins). Side effects of these non-steroidal drugs include headache, nausea, nervousness, diarrhea, perspiration, hot flushes, and bone pain [165].

\section{Gym rats: AAS reinforcement and dependence in animals}

Animal studies have been useful to evaluate the reinforcing effects of androgens. Animal studies showing testosterone conditioned place preference and self-administration demonstrate that testosterone is reinforcing in an experimental context where anabolic effects and athletic performance are irrelevant. The first reports of androgen reward in laboratory animals used conditioned place preference $(\mathrm{CPP})$ in male mice $[7,8]$ and rats $[3,45]$. Animals paired four times for $30 \mathrm{~min}$ following systemic injections of testosterone at $0.8-1.2 \mathrm{mg} / \mathrm{kg}$ sc developed a preference for the conditioning chamber. Subsequently, our laboratory used self-administration of testosterone to demonstrate androgen reinforcement. We found that male hamsters will voluntarily consume oral solutions of testosterone using both 2-bottle choice tests and food-induced drinking [85]. In later studies, we demonstrated iv selfadministration in male rats and hamsters [185]. Animals that have the opportunity to self-administer testosterone at $50 \mu \mathrm{g} /$ injection for $4 \mathrm{~h} /$ day via an indwelling jugular catheter will develop a preference for the active nose-poke that controls testosterone delivery. This eliminates potential confounding effects of taste or gut fill on androgen intake.

In the context of AAS abuse, it is important to differentiate between central and peripheral effects of androgens. Since testosterone has widespread effects throughout the body, it could be argued that reward and reinforcement with sc or iv testosterone injections is secondary to testosterone's systemic anabolic and androgenic actions. In other words, may be testosterone reduces muscle fatigue and improves joint function so that animals just feel better. Indeed, this explanation has been used in the clinical literature (albeit without experimental evidence) to argue against the potential for dependence and addiction to AAS [53]. Packard et al. [123] showed that injections of testosterone directly into the brain can produce a place preference. Likewise, our laboratory has demonstrated intracerebroventricular (icv) testosterone self-administration in male hamsters [185] (Fig. 2). For these studies, each operant response delivers $1.0 \mu \mathrm{g}$ testosterone in $1.0 \mu \mathrm{l}$ of an aqueous vehicle. Importantly, hamsters do not self-administer the cyclodextrin vehicle alone. Intracerebral CPP and icv self-administration with testosterone argue for central androgen reinforcement.

\subsection{A few provisos, a couple of quid pro quos}

Frequently, we are asked how androgen self-administration in rodents compares with human AAS use. Naturally, it is difficult to compare a Syrian hamster $(150 \mathrm{~g})$ or a rat $(250 \mathrm{~g})$ with an average American man $(86 \mathrm{~kg}$, according 


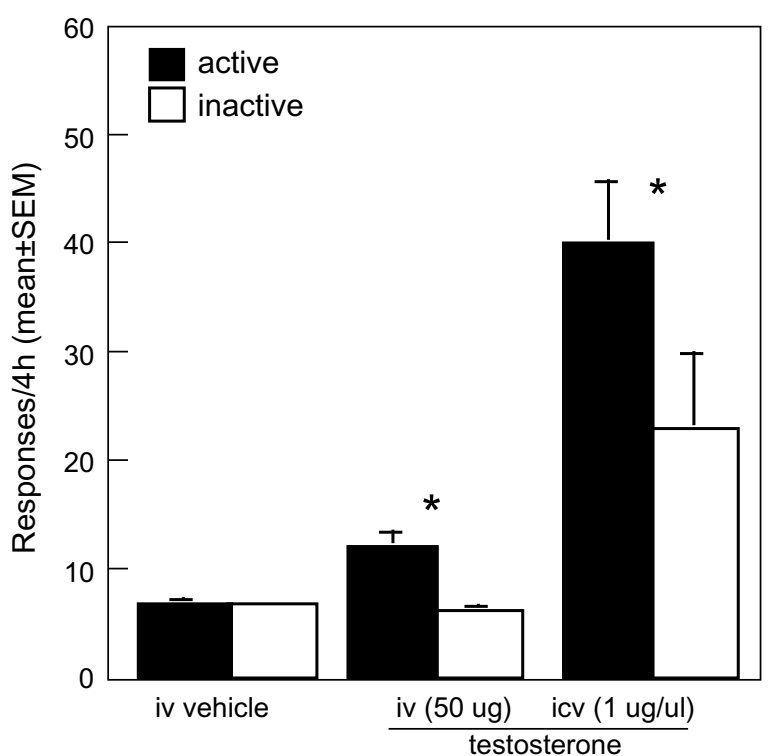

Fig. 2. Operant responding for testosterone or vehicle ( $\beta$-cyclodextrin) in male hamsters (mean \pm SEM). During daily 4-h test sessions, hamsters acquire a significant preference for the active nose-poke (closed bars) over the inactive nose-poke (open bars) when self-administering testosterone iv or icv. Asterisks indicate significant preference for the active nose-poke. Redrawn from [185].

to the National Center for Health Statistics [118]). Nonetheless, on a per kg bodyweight basis, systemic testosterone intake by iv self-administration in hamsters and rats appears to fall within the range for human AAS use. Human AAS doses range from $\leqslant 600 \mathrm{mg} /$ week in clinical studies $[140,175]$ to $>2000 \mathrm{mg} /$ week in fitness websites [170]. When male hamsters are tested for iv self-administration in $4 \mathrm{~h}$ sessions $5 \mathrm{x} /$ week, daily testosterone intake averages $342 \mu \mathrm{g}$ [185]. Scaled to human body weight (BW), this is equivalent to $900 \mathrm{mg} /$ week. Other investigators testing AAS in animals have used even higher equivalent doses (ca. $1600-3000 \mathrm{mg} /$ week $[58,110]$ ). It is important to point out that icv testosterone intake is substantially below the normal range for human use. Hamsters averaged $27 \mu \mathrm{g}$ testosterone over $4 \mathrm{~h}$ by icv self-administration [185], equivalent to $80 \mathrm{mg} /$ week when scaled to human BW. Despite this low-dose, testosterone is even more reinforcing when selfadministered icv compared with iv self-administration. This further supports the argument for central androgen reinforcement.

The route of administration is another concern when comparing AAS use in humans and animals. As far as modeling patterns of clinical AAS use, humans do not take steroids either by iv or icv injection. Instead, AAS users take steroids orally, transdermally, or by intramuscular (im) injection [22]. A typical steroid user might begin using oral steroids and progress to the more potent injectable androgens, perhaps supplemented with transdermal testosterone preparations [168]. In hamsters and rats, we have demonstrated AAS self-administration orally [85,184], and by iv [185] or icv injection $[11,50,51,131,132,176,185]$.
It is unlikely that animals would voluntarily self-administer steroids by im injection (even steroid users acknowledge that the injections are painful), and it seems unfeasible to test transdermal self-administration in furry animals. Although oral self-administration is relevant to human use, this method has several disadvantages. Robust absorption into systemic circulation is compromised due to uptake across the gut and first-pass metabolism in the liver [105]. Each AAS has a unique profile of uptake and metabolism. Hence, the amount of androgen delivered to the brain varies with the specific AAS. Moreover, the 17 $\alpha$ alkylated androgens designed for oral use are hepatotoxic [39]. Finally, it is worth noting that other drugs of abuse are routinely tested for self-administration in animals via routes that are not clinically significant. While humans ingest nicotine by smoking or in smokeless tobacco [119], rats self-administer nicotine iv [40] or orally in drinking water [100].

Finally, what's so special about hamsters? Nothing, really. Would other animals (rats, mice, monkeys) show similar responses for testosterone self-administration? Probably. At present, reinforcing effects of androgens have been demonstrated in mice (CPP $[7,8])$, rats (CPP, iv and icv self-administration $[3,45,62,63,87,95,123,124,144$, $150,155,185])$ and hamsters (oral, iv, icv self-administration $[11,50,51,86,131,132,176,184,185])$; there is no evidence for substantial species differences. Males of most laboratory rodent species are highly sensitive to gonadal steroids for expression of sexual behavior and aggression $[79,114]$. Castrated males will not mate, and agonistic behavior is severely reduced. Both are restored by exogenous androgen at physiologic concentrations [79,114], and are enhanced by androgen treatment at pharmacologic levels $[58,74,184]$. Furthermore, the distribution of androgen (AR) and estrogen receptors (ER) in the brain is similar among rodent species $[159,160,186,187]$.

\subsection{Not your father's drugs: sex differences and effects of circulating androgens}

As we try to understand the effects of AAS, it is helpful to consider who is using these compounds. It has been estimated that over 1 million people in the U.S. have used AAS [168]. However, individuals with the highest endogenous androgens are also the most likely to use AAS. The median age for first time AAS use (18 years of age [148]) correlates with peak serum testosterone levels in men [10]. The incidence of AAS use in young adult men is substantially greater compared to men with lower circulating androgen levels, including prepubertal boys and older men [148]. This suggests that circulating androgens enhance responsiveness to exogenous androgens. We tested this hypothesis by comparing icv testosterone self-administration in orchidectomized male hamsters with and without chronic androgen replacement [50]. Regardless of circulating androgen levels, both groups of males self-administered testosterone at 1.0 or $2.0 \mu \mathrm{g} / \mu \mathrm{l}$. However, responsiveness to 
dilute solutions of testosterone was reduced in castrated males without testosterone replacement. Castrated males did not develop a preference for the active nose-poke during icv self-administration of testosterone at $0.1 \mu \mathrm{g} / \mu \mathrm{l}$, while castrates with systemic testosterone replacement did (Fig. 3). Thus, it appears that endogenous androgens may sensitize the brain to exogenous AAS, thereby enhancing the drive to use more AAS.

From the foregoing data, it is perhaps not surprising that AAS use is more common in men than in women $[86,148]$. This could be due, at least in part, to sex differences in the reinforcing effects of androgens. There is prec-

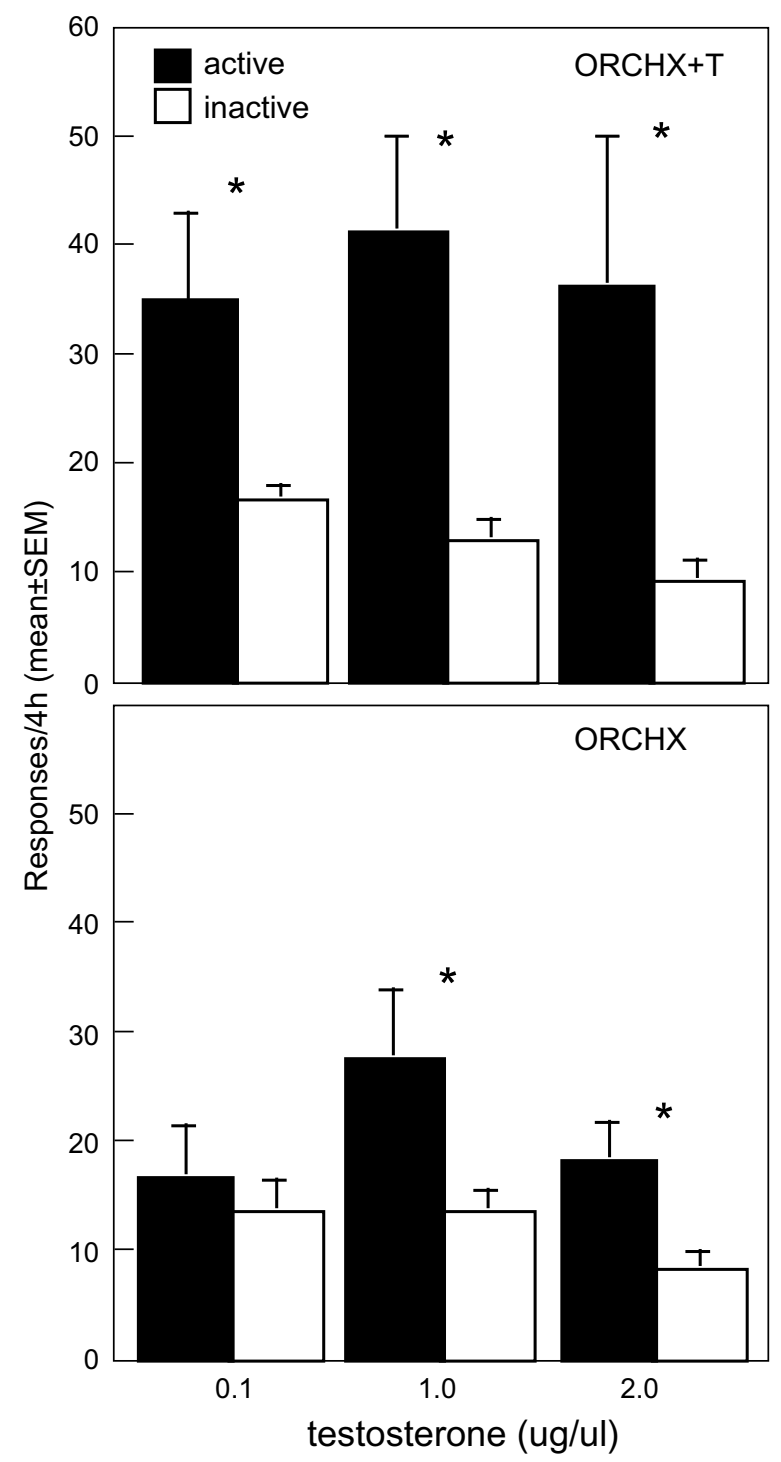

Fig. 3. Operant responding for testosterone in castrated male hamsters with (ORCHX $+\mathrm{T}$, top) and without (ORCHX, bottom) systemic androgen replacement (mean $\pm \mathrm{SEM})$. During daily 4-h test sessions, $\mathrm{ORCHX}$ and $\mathrm{ORCHX}+\mathrm{T}$ hamsters acquire a significant preference for the active nose-poke (closed bars) over the inactive nose-poke (open bars) when self-administering testosterone icv at 1.0 or $2.0 \mu \mathrm{g} / \mu \mathrm{l}$. However, only $\mathrm{ORCHX}+\mathrm{T}$ developed a preference for the active nose-poke at $0.1 \mu \mathrm{g} / \mu \mathrm{l}$ testosterone. Asterisks indicate significant preference for the active nosepoke. Redrawn from [50]. edent for reduced behavioral responses to androgens in females: testosterone stimulates masculine sexual behavior, flank marking and aggression in male rodents, but not in females [79,114]. Furthermore, females have fewer brain androgen receptors [186]. Only a few studies have investigated androgen reward in female animals. Early studies of DeBeun et al. [45] reported that female rats failed to form a CPP even at $3 \mathrm{mg} / \mathrm{kg}$. More recent studies have shown that female rats will show CPP in response to estradiol [87]. Furthermore, we have demonstrated icv testosterone self-administration in female hamsters [176]. In our study, operant responding for testosterone in females was similar to that in castrated males. That is, female hamsters showed robust responses for testosterone at 1.0 or $2.0 \mu \mathrm{g} / \mu \mathrm{l}$, but failed to develop a preference for the active nosepoke at $0.1 \mu \mathrm{g} / \mu \mathrm{l}$ testosterone (Fig. 4). Therefore, we conclude that AAS are reinforcing in both sexes. Compared with ovary-intact females, gonad-intact males are more sensitive to dilute solutions of testosterone, presumably due to the higher levels of endogenous androgen in circulation.

At first glance, these animal data demonstrating similar responses for androgens in males and females would appear to contradict the profound sex difference in human AAS use. Among American high school students, it is estimated that $4-6 \%$ of men have used AAS, compared with only $1-2 \%$ of women [190]. In fact, a similar disconnect between prevalence of use and drug responsiveness emerges when evaluating sex differences for most drugs of abuse. In national surveys, drug use is more common in men: $38 \%$ of men aged 18-25 have used an illicit drug in the past year,

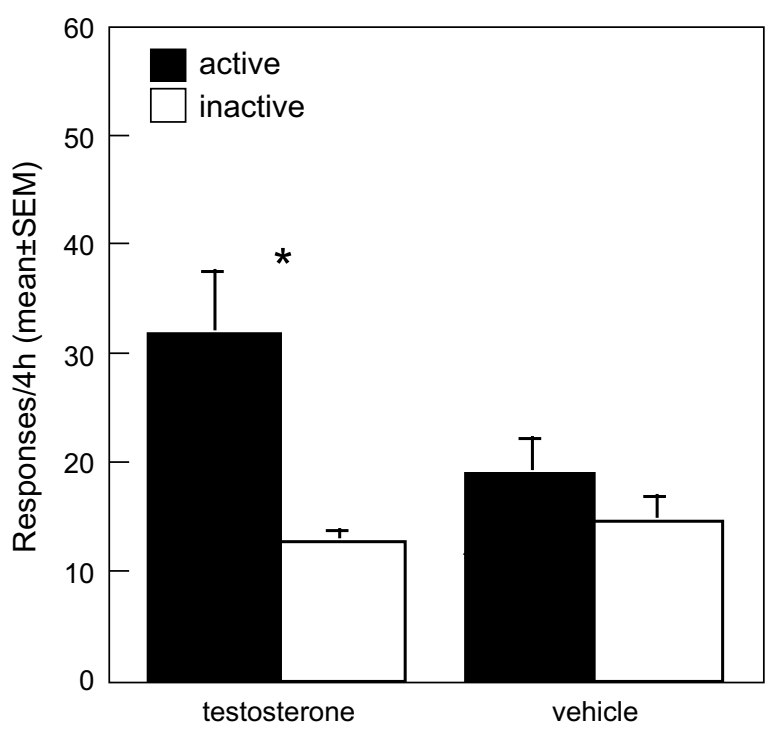

Fig. 4. Operant responding for testosterone or vehicle ( $\beta$-cyclodextrin) in female hamsters (mean \pm SEM). During daily 4-h test sessions, ovaryintact female hamsters acquire a significant preference for the active nosepoke (closed bars) over the inactive nose-poke (open bars) when selfadministering testosterone icv, but not during vehicle self-administration. Asterisks indicate significant preference for the active nose-poke. Redrawn from [176]. 
compared with only $30 \%$ of women [149]. However, laboratory studies of stimulants, opioids, caffeine, alcohol, and phencyclidine demonstrate that females may be even more responsive than males [145].

Therefore, it would appear that other factors, both physiologic and social, are responsible for the lower incidence of AAS use in women. Women using AAS experience more severe and irreversible side effects, and this may be a powerful deterrent [128]. For athletes, the decision to use AAS is affected by perceptions of steroid use among other competitors [64], and steroid use among female athletes remains relatively uncommon. For the non-competitor in pursuit of the "ideal" body type presented in popular media, a lean physique is favored in both sexes, but heavy musculature is considered desireable only in men [135]. Finally, the true incidence of AAS use by women remains unclear. It has been suggested that women may underreport steroid use in surveys because they are more secretive about their use of such agents [191]. However, improperly phrased questions may also have led to an over-reporting of AAS use, particularly among adolescent girls [90].

\section{Can't beat the real thing: reinforcing effects of AAS vs testosterone and its metabolites}

Testosterone is a logical choice for exploring fundamental mechanisms of androgen reward. However, we are often asked to comment on the abuse liability of "the steroids that people really use". It is important to emphasize here that testosterone remains a popular choice for human users, most often in the form of long-acting testosterone esters such as testosterone propionate. Although esterification prolongs the half-life in circulation, the active steroid is still testosterone. In 2006, testosterone was the single most-common banned substance detected in urine tests at WADA-accredited laboratories, representing $26 \%$ of all "adverse analytical findings" [181]. Cannabinoids were in second place (13\% of positive tests), while nandrolone was 4 th (5.5\% of positive tests), behind the $\beta 2$ agonist salbutamol. Testosterone accounted for the largest fraction (34\%) of AAS-positive urine tests at the 2000 Sydney Olympic Games; nandrolone was detected in 32\% [178]. Likewise, in urine tests of AAS users, nandrolone was present in $57 \%$, and $41 \%$ tested positive for testosterone [26].

Although current evidence suggests that testosterone is a popular choice among steroid users, it is important to consider the factors which contribute to a positive urine test for different AAS. With banned substances of exogenous origin, it is comparatively easier to establish acceptable limits. For example, a urinary concentration of 19-norandrosterone (the principal urinary metabolite of nandrolone) $>2 \mathrm{ng} / \mathrm{ml}$ constitutes an "adverse analytical finding" [179]. By contrast, testosterone and other endogenous steroids are normally present in urine samples, and the concentrations vary considerably: from 30 to $120 \mathrm{ng} / \mathrm{ml}$ among normal men [54]. Accordingly, WADA-accredited laboratories rely on the ratio of testosterone to epitestosterone (a naturally occurring isomer of testosterone) to screen urine samples for exogenous testosterone intake, and a $T / E$ ratio exceeding $4: 1$ is evaluated for further testing [180]. This highlights one of the paradoxes of testosterone as a drug of abuse. At physiologic concentrations, testosterone is essential for reproduction and contributes to other aspects of normal adult function. However, at high doses, the effects of testosterone can spill over to affect other systems. Although testosterone is a naturally occurring hormone, it is nonetheless a steroid with both anabolic and androgenic properties. Thus, it is appropriate to group testosterone along with exogenous androgens as AAS.

In fact, exogenous androgens are not so different from endogenous hormones. Despite the variety of trivial names, brand names, and "street" names (methandrostenolone, Dianabol, D-bol for 17 $\beta$-hydroxy-17 $\alpha$-methyl-1,4-androstadien-3-one), all AAS are derived from testosterone. All AAS have a carbon skeleton with 4 fused rings; most have 19 carbons. For example, nandrolone is formed from testosterone by substitution of a hydroxyl group for a methyl group at the C-10 position. Similarly, stanozolol is produced by alkylation of testosterone at the $\mathrm{C}-17$ position.

Nonetheless, to compare the reinforcing efficacy of different AAS, a recent study from our laboratory tested icv self-administration of drostanolone, nandrolone, oxymetholone, and stanozolol in male hamsters [11]. Drostanolone and nandrolone are highly androgenic injectable steroids, while oxymetholone and stanozolol are less potent orally active androgens. Importantly, oxymetholone and stanozolol are neither reducible into highly androgenic compounds nor aromatizable to estrogens. Self-administration of drostanolone and nandrolone was comparable to that of testosterone, but hamsters did not self-administer oxymetholone or stanozolol across a 20 -fold range of concentrations (Fig. 5). While we cannot generalize from these results to all AAS, it would appear that the reinforcing efficacy of a particular AAS is related to its androgenic potency.

Further investigations using CPP and self-administration have worked to identify the specific testosterone metabolites that mediate androgen reinforcement. Testosterone can be metabolized to dihydrotestosterone (DHT) via the $5 \alpha$-reductase enzyme or aromatized to estradiol. Both testosterone and DHT bind to androgen receptors (AR), although DHT has higher AR binding affinity than testosterone [146]. Estradiol is the principal ligand for estrogen receptors (ER), including both $\alpha$ and $\beta$ forms of ER. As demonstrated either by CPP in rats [144] or icv self-administration in hamsters [51], DHT is reinforcing at doses comparable to those for testosterone reward (Fig. 6). Estradiol is also reinforcing, as determined by icv self-administration in male hamsters [51] and CPP in female rats [87]. However, compared with DHT or testosterone, the doses for estradiol reinforcement are much lower. Male hamsters will self-administer estradiol at $0.1 \mu \mathrm{g} / \mu \mathrm{l}$ (vs $1.0 \mu \mathrm{g} / \mu \mathrm{l}$ for DHT). Likewise, ovariectomized 


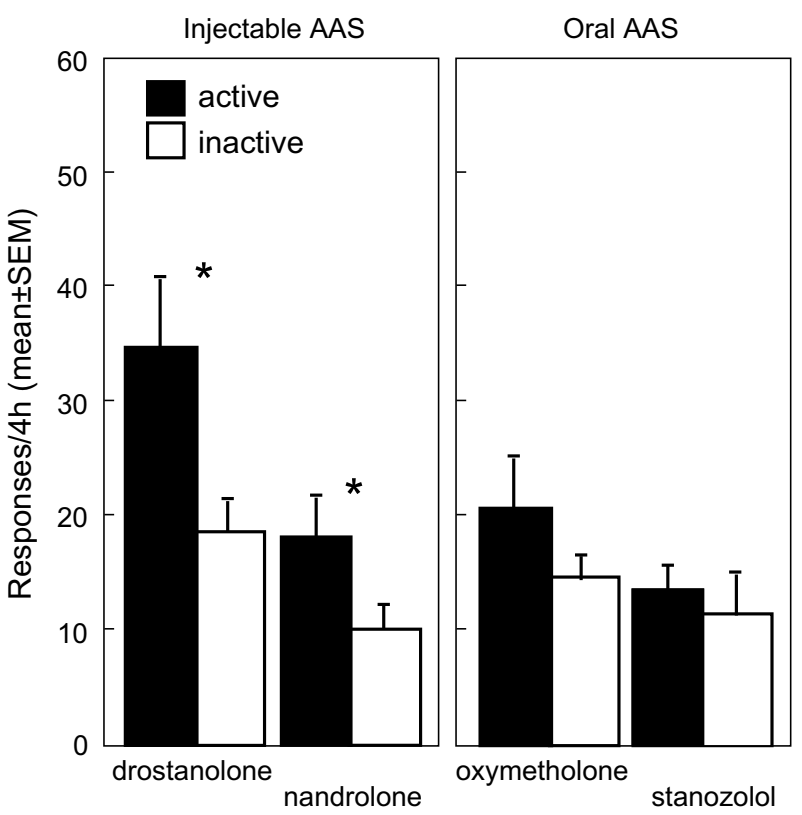

Fig. 5. Operant responding for 2 injectable anabolic-androgenic steroids (AAS: drostanolone, nandrolone) and 2 oral AAS (oxymetholone, stanozolol) in male hamsters (mean $\pm \mathrm{SEM}$ ). During daily 4-h test sessions, hamsters acquire a significant preference for the active nosepoke (closed bars) over the inactive nose-poke (open bars) when selfadministering drostanolone or nandrolone icv at $1.0 \mu \mathrm{g} / \mu \mathrm{l}$, but not during self-administration of oxymetholone or stanozolol. Asterisks indicate significant preference for the active nose-poke. Redrawn from [11].

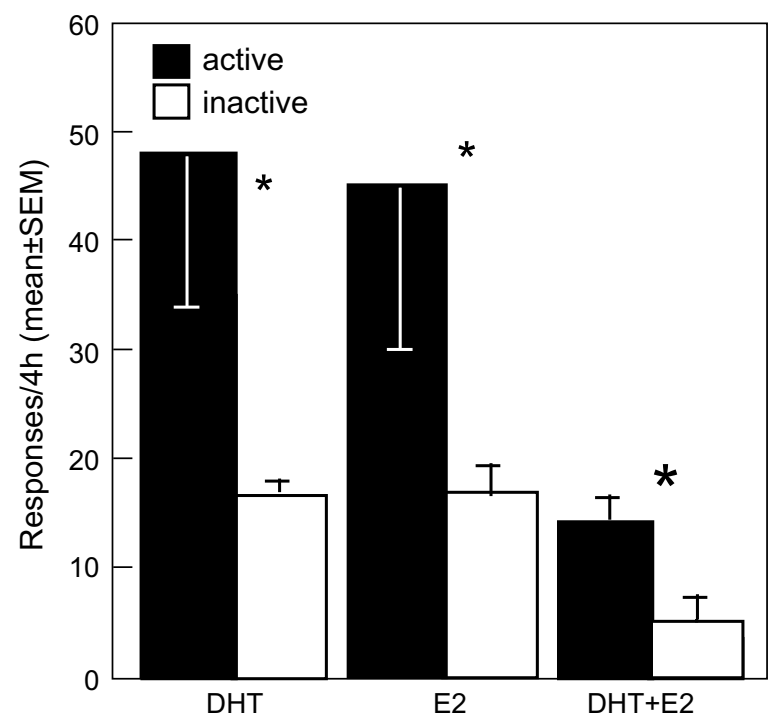

Fig. 6. Operant responding for dihydrotestosterone (DHT), estradiol (E2) or their combination (DHT + E2) in male hamsters (mean $\pm \mathrm{SEM}$ ). During daily 4-h test sessions, hamsters acquire a significant preference for the active nose-poke (closed bars) over the inactive nose-poke (open bars) when self-administering either DHT, E2, or DHT + E2 icv, but not during self-administration of oxymetholone or stanozolol. Asterisks indicate significant preference for the active nose-poke. Redrawn from [51].

female rats will shown CPP in response to $0.03 \mathrm{mg} / \mathrm{kg}$ estradiol [182] (vs $3.0 \mathrm{mg} / \mathrm{kg}$ for DHT-induced CPP [62]). This reflects the increased potency of estradiol and the low concentrations of estrogen in circulation. Circulating concentrations of estradiol in female hamsters are ca. 1000 -fold lower than circulating androgens in males [12,103]. Moreover, in gonadectomized male hamsters, mating behavior can be stimulated with only $1.0 \mu \mathrm{g}$ of estradiol vs $300 \mu \mathrm{g}$ of testosterone $[28,158]$.

From these studies, it would appear that either androgens or estrogens are reinforcing. Somewhat surprisingly, we observed lower levels of operant responding when hamsters self-administered both DHT and E2 together [51]. From these data, it is tempting to speculate that the reinforcing effects of androgens and estrogens may be mediated by different and possibly antagonistic mechanisms. However, this remains untested. Indeed, recent findings have blurred the distinction between androgens and estrogens. DHT can be further metabolized in brain to $5 \alpha$-andro-

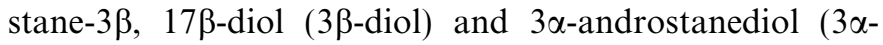
diol) by $3 \alpha$-hydroxysteroid dehydrogenase (HSD), $3 \beta$ HSD and $17 \beta$-HSD [81,162]. $3 \beta$-diol and $3 \alpha$-diol are significant in view of recent reports suggesting that $3 \alpha$-diol induces CPP in male [144] and female rats [87], and that $3 \beta$-diol binds to $\operatorname{ER} \beta[125]$.

\section{This is your brain on steroids: central targets of AAS action}

The foregoing studies comparing reinforcement with different steroid hormones form an essential backdrop for understanding where and how AAS act in the brain to cause reinforcement. The brain has AR and ER, plus the major steroid metabolic enzymes: $5 \alpha$-reductase, aromatase, $3 \alpha$-HSD, $3 \beta-H S D$, and $17 \beta-H S D$ [32]. AR and ER $\alpha$ are most abundant in basal telencephalon and diencephalon $[157,159,160,186,187]$, particularly in brain regions that control steroid-dependent social behavior. Historically, research on steroid action in the brain has focused on regions with large populations of steroid receptors, which are typically concentrated in the neuronal cell nucleus. According to the model developed from these early studies, "classical" AR and ER function as transcription factors to induce transcription and synthesis of new proteins. Not surprisingly, these effects follow a slow time-course, with a delayed onset and relatively persistent action. Steroid stimulation of male sexual behavior is consistent with actions through classical genomic actions [120].

With continued research, a more nuanced picture has emerged. Although AR and ER are concentrated in limbic nuclei, the receptors are widely distributed throughout the brain. This is consistent with the diverse effects of steroids on neural function, including cognition, memory, motor function, and mood [55,60]. In addition to actions via $\mathrm{AR}$ and $\mathrm{ER} \alpha$, some behavioral effects of steroids are mediated through ER $\beta$ receptors [15]. At the cellular level, steroids are not limited to transcriptional effects on DNA [166]. Instead, steroids have actions in the cytoplasm and at the plasma membrane to modify kinase activity, ion channels, and G-protein second-messenger systems [19]. 
Collectively, these are considered non-genomic effects, some of which include binding to AR and ER. Recent studies have also demonstrated rapid effects of androgens and estrogens in brain regions that possess few classical receptors [112]. Thus, the rewarding effects of AAS have the potential to act in the brain through classical AR, through classical estrogen receptors (ER) after local metabolism to estradiol or 3 $\beta$-diol [125], or may be independent of either AR or ER [36]. The specific details remain to be resolved. Indeed, more than one mechanism may contribute to AAS reinforcement. However, the time-course of steroid exposure in the conditioned place preference test $(30 \mathrm{~min})$ is short. This is consistent with actions via non-genomic steroid receptors.

In terms of brain site(s) of action, testosterone reinforcement does not necessarily follow the same mechanisms for steroid effects on social behavior. The medial preoptic area (MPOA) is a key site for organization of male sexual behavior (reviewed in $[78,79]$ ). MPOA has abundant classical AR and ER, and testosterone implants in MPOA restore sexual activity in long-term castrates. The timecourse of these steroid effects is slow: mounting behavior persists for weeks after orchidectomy, and extended steroid exposure is necessary to restore mating in long-term castrates. However, injections of testosterone into MPOA of male rats fail to induce CPP [95], suggesting that other brain regions are important for androgen reinforcement.

One way to get at this question is through the use of the immediate-early gene product Fos. When hamsters selfadminister testosterone icv, we presume that steroids can diffuse throughout the brain. However, we can use Fos expression to map neuronal activation in response to icv androgen infusion. A $4 \mathrm{~h}$ infusion of $40 \mu \mathrm{g}$ testosterone icv stimulates Fos in the medial amygdala (Me), and bed nucleus of the stria terminalis (BST), [52]. Me and BST have abundant AR and ER, and contribute to hormonal control of sexual behavior [187]. However, Fos is also expressed in the ventral tegmental area (VTA), suggesting that AAS may act preferentially through VTA, similar to ethanol [80] and morphine [17] (Fig. 7).

\subsection{Dopamine}

VTA is a part of the mesolimbic dopamine (DA) system, consisting of midbrain dopaminergic neurons in VTA and their projections to the nucleus accumbens (Acb) and related structures in the basal forebrain [47]. Drugs of abuse act on the mesolimbic DA system to increase DA release (amphetamine, opiates), or reduce DA reuptake by nerve terminals in Acb (cocaine) [17]. Moreover, rats will self-administer many drugs directly into Acb or VTA $[43,143]$, and selective DA lesions attenuate the rewarding properties of food, sex, and drugs [147].

Although we did not observe an increase in Fos expression in Acb in response to icv testosterone, a variety of evidence suggests that the activity of the mesolimbic DA system is involved in androgen reinforcement. Male rats

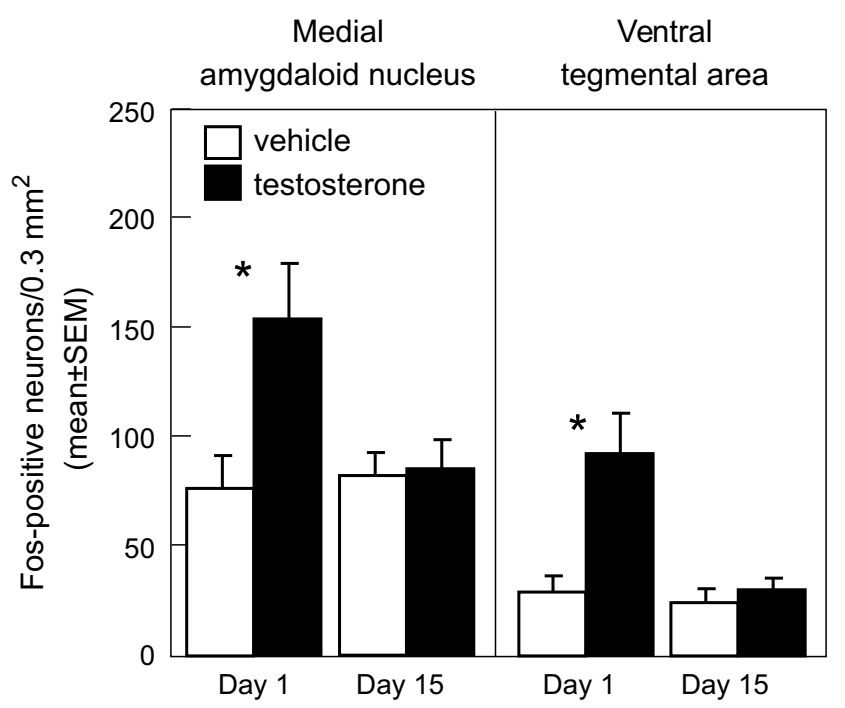

Fig. 7. Testosterone-induced Fos in the medial amygdaloid nucleus (left) and ventral tegmental area (right) in male hamsters (mean \pm SEM). Hamsters were perfused immediately following a 4-h icv infusion of testosterone (closed bars) or vehicle (open bars), either on the first day (Day 1) or after 15 days of icv infusion (Day 15). Asterisks indicate significant increase in the number of Fos-positive neurons compared with vehicle controls. Redrawn from [52].

will form a place preference when testosterone [123], DHT, or 3a-diol [62] is injected directly into Acb. Systemic or intra-Acb treatment with the mixed D1/D2 antagonist $\alpha$-flupenthixol blocks testosterone-induced CPP in male rats [124]. Furthermore, CPP induced by systemic testosterone injection is blocked by intra-Acb injections of either D1-like (SCH23390) or D2-like (sulpiride) DA receptor antagonists [155]. In support of these animal studies, human volunteers receiving weekly nandrolone injections demonstrated an increase in serum levels of the dopamine metabolite homovanillic acid [72]. Nonetheless, the specific mechanisms through which AAS and DA interact are still unclear. Thiblin et al. [171] observed an increase in DA synthesis in response to methandrostenolone, and nandrolone stimulates the DA metabolite 3,4-dihydroxyphenylacetic acid (DOPAC) in cerebral cortex [99]. On the other hand, as measured by in vivo microdialysis with HPLC, testosterone does not appear either to stimulate Acb DA release [177], or to potentiate amphetamine-stimulated DA in Acb [13]. Furthermore, Acb and VTA have few classical androgen receptors [97], suggesting that the reinforcing effects of intra-Acb androgens may be mediated by non-genomic receptors.

\section{2. $G A B A$}

Although the mesolimbic DA system is central to drug reinforcement, other transmitter systems also play a role. A variety of evidence links AAS with the brain's principal inhibitory neurotransmitter GABA (reviewed in [35]). In this manner, AAS may share similarities with barbiturates, alcohol, and sedative-hypnotic drugs, such as benzodiaze- 
pines. Like benzodiazepines, testosterone and its derivatives (including $3 \alpha$-diol) have anxiolytic effects, as demonstrated by spending more time in the open arms of an elevated plus-maze in mice [2] and with performance in open field, defensive burying, and social interaction tests in rats [63]. These behavioral effects are likely to be mediated via changes in the GABAa receptor [88]. Specifically, AAS decrease the levels of individual GABAa receptor units, and modify GABAergic transmission in selected brain regions related to fear and anxiety [35]. These data from animal studies fit with clinical observations of AAS use in humans. While on steroids, AAS users report that they feel "pumped and invincible" (http://www.nutritionalsupplements.com/roider.html): "It feels as if I am superman and I act like it", “...I can'Conquer anything." Conversely, during steroid withdrawal, feelings of depression and anxiety predominate: "I'm just getting off my steroids...Depression, shakes, weight gain, zits, 3-4 hs of sleep a day, hyper, jitters...”.

Although androgen withdrawal has not been systematically studied in animals, there are a limited number of reports suggesting that discontinuing high-dose androgens or acutely blocking androgen action may have behavioral consequences. In most animals, testosterone stimulates aggression in males $[58,74,114]$. It is therefore somewhat surprising that withdrawal from AAS also increases agonistic behavior in response to physical provocation by the experimenter [83,109]. Accordingly, it is tempting to speculate that steroid withdrawal makes animals more irritable, similar to clinical reports from human users.

\subsection{Serotonin}

Steroids-induced changes in the serotonergic system also appear to contribute to behavioral responses to AAS, particularly agonistic behavior. In hamsters, adolescent exposure to AAS enhances aggression [110], and this effect is attenuated by pharmacologic treatments to increase serotonergic activity, either via the selective serotonin reuptake inhibitor fluoxetine [68] or the 5HT1A receptor agonist 8OH-DPAT [142]. As with other neurotransmitter systems, there are region-specific changes in levels of serotonin and its receptors in response to AAS exposure. Specifically, AAS treatment reduces serotonin in basal forebrain and dorsal striatum [102], including loss of fiber staining in brain regions controlling aggression and social behavior: $\mathrm{Me}$, and the anterior $(\mathrm{AH})$ and ventrolateral hypothalamus [68]. In AH, 5HT1A receptors are also reduced [142], while 5HT1B receptors are down-regulated in the medial globus pallidus and the CA1 region of hippocampus [94]. By contrast, AAS increase serotonin levels in cerebral cortex [99], and 5HT2 receptors in Acb [94]. In male volunteers receiving injections of methyltestosterone, levels of the serotonin metabolite 5-hydroxyindolacetic acid in cerebrospinal fluid increased, and this was correlated with activation symptoms: energy, sexual arousal, diminished sleep [42]. Most significantly, Grimes and Melloni [69] have shown that changes in the serotonergic system persist long after steroid is discontinued. This suggests that AAS exposure, particularly during the adolescent period, may cause long-lasting behavioral sensitivity.

\subsection{Opioids}

Initially, because of the strong association of AAS with athletics and aggression, it seemed logical that pharmacologic androgens might act as stimulants. Instead, my laboratory was struck by similarities between the effects of AAS and opiates. This began with our unexpected observation that excessive androgen intake in hamsters self-administering testosterone icv could cause a fatal overdose [131]. During 1-56 days of androgen self-administration, 10 of 42 $(24 \%)$ hamsters died. Testosterone overdose was related to peak daily intake: at $<20 \mu \mathrm{g} /$ day, there were no deaths. With peak intake of $20-60 \mu \mathrm{g} /$ day, $86 \%$ survived. However, when testosterone intake exceeded $60 \mu \mathrm{g} /$ day, only $30 \%$ survived. It is notable that none of the animals died during self-administration. Instead, testosterone infusion caused a profound autonomic depression, and hamsters often died several days later despite supportive care. We hypothesize that death is by cardiac arrest secondary to hypothermia. Androgeninduced hypothermia has previously been reported in mice [29], and profound hypothermia can produce fatal cardiac arrhythmia [6]. Anabolic steroids are also associated with bradycardia and cardiac arrhythmias $[92,164]$.

To probe this response further, we recorded locomotor activity, body temperature and respiration following daily icv infusions of a sub-lethal dose of testosterone icv $(40 \mu \mathrm{g})$. During the first few days of testosterone infusion, locomotion, respiration and body temperature were all substantially depressed (Fig. 8). However, males developed tolerance to continued daily testosterone infusion. After 15 days of testosterone infusion, locomotion, respiration, and body temperature in testosterone-infused males were equivalent to that in vehicle controls. This finding is significant because tolerance is a key criterion for drug dependence [96].

Because the symptoms of testosterone overdose resemble opiate intoxication, we tested if the opioid antagonist naltrexone would block the depressive effects of testosterone infusion. With $5 \mathrm{mg} / \mathrm{kg}$ naltrexone pretreatment, locomotion, respiration, and body temperature during testosterone infusion were equivalent to vehicle controls. These results suggest that testosterone at pharmacologic doses causes death by central autonomic depression, and this effect may be mediated by an opioidergic mechanism. Likewise, naltrexone prevents the reinforcing effects of icv testosterone self-administration. Hamsters pretreated with naltrexone failed to develop a preference for the active nose-poke during testosterone self-administration (Fig. 9). These data implicate the opioid system in mediating the effects of pharmacologic androgens.

On the other hand, testosterone does not precisely mimic opioid effects. When hamsters receive an injection 


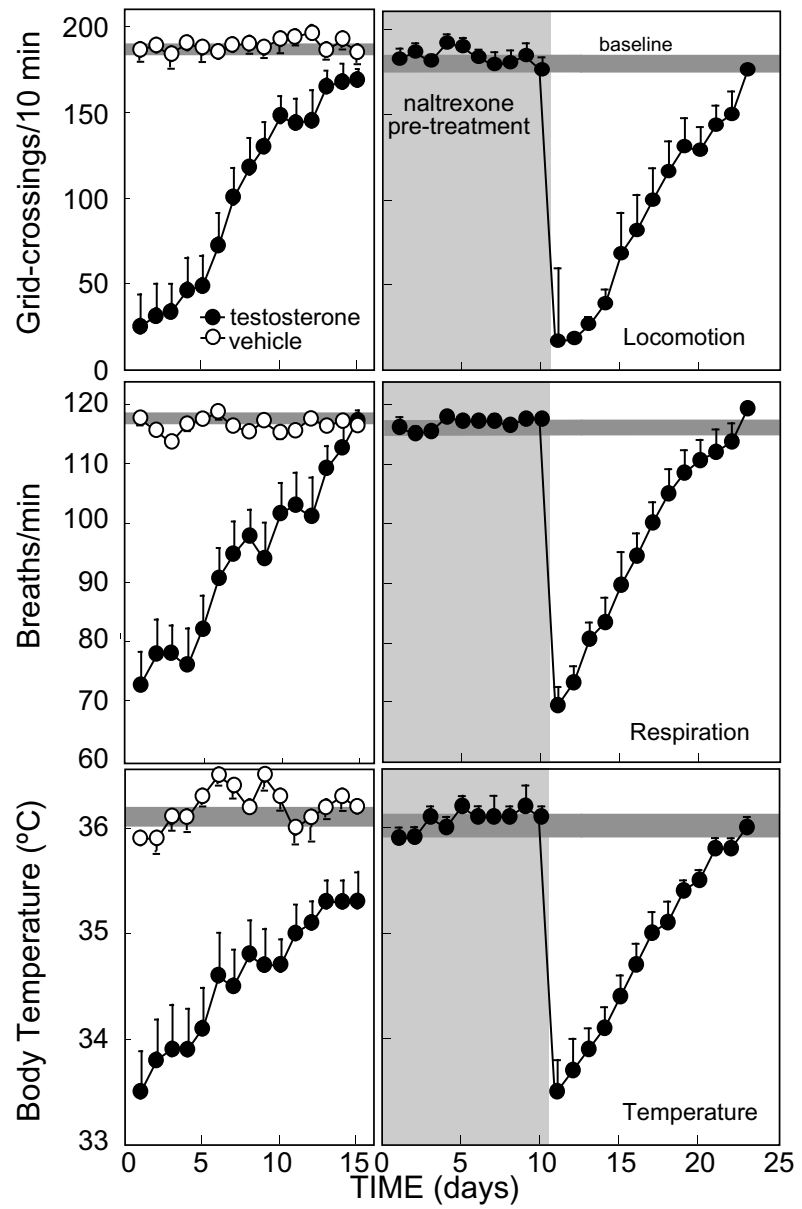

Fig. 8. Left: Daily 4-h infusions of testosterone icv (closed symbols) initially inhibit locomotor activity (top), respiration (middle) and body temperature (bottom) in male hamsters compared with hamsters receiving icv infusions of vehicle (open symbols). The gray bar indicates baseline measures for both groups before icv infusions. Over time, hamsters develop tolerance to repeated testosterone infusions. Right: Pretreatment with the opioid antagonist naltrexone (shaded area) blocks the depressive symptoms of testosterone infusion. Redrawn from [131].

of naloxone following icv testosterone infusion, it is significant that we did not observe classic symptoms of opiate withdrawal (wet-dog shakes, paw shakes, teeth chattering, abdominal writhing, yawning, and defecation [152-154]). Similar findings have been reported for rhesus monkeys treated with naloxone following testosterone propionate [117]. Thus, it may be that testosterone serves as a partial opioid agonist and/or may act through non-opioid systems.

There is precedent for an interaction of androgens and opioids in the brain in animal studies [73,82-84]. The specific interaction (synergistic vs antagonistic) may depend on the type of opioid receptors and the specific brain regions involved. In this regard, high-dose morphine causes hypothermia through actions on kappa opioid receptors, and nandrolone enhances this effect in mice [31]. Likewise, Stoffel et al. [161] have shown that testosterone enhances the antinociceptive effects of the kappa agonist U50,488. Other studies have found no effect of AAS on morphine

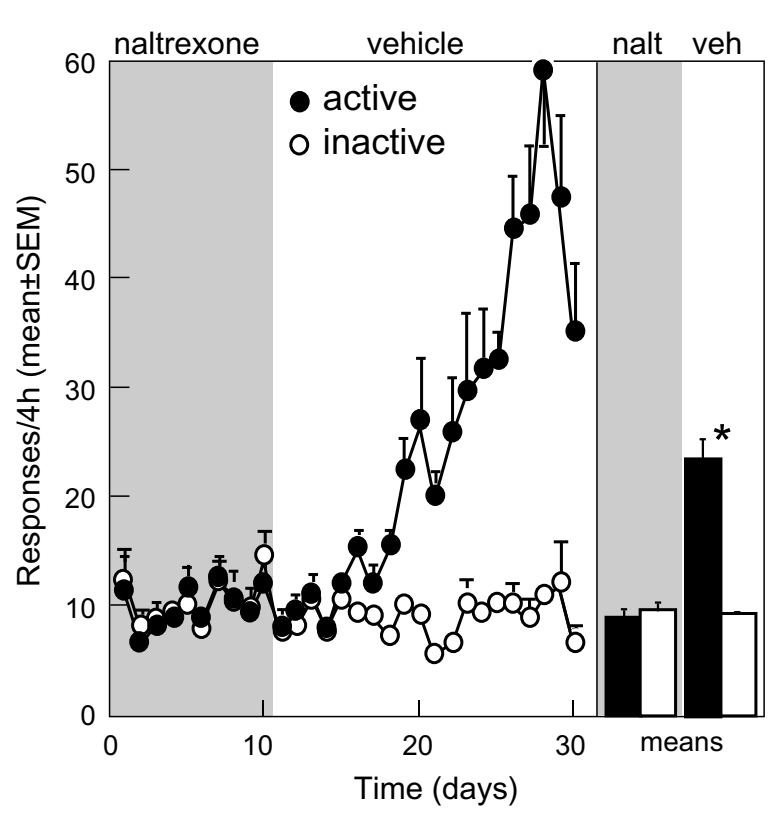

Fig. 9. Operant responding for testosterone in male hamsters (mean \pm SEM). During daily 4-h test sessions, hamsters acquire a significant preference for the active nose-poke (closed symbols) over the inactive nose-poke (open symbols). Pretreatment with the opioid antagonist naltrexone (shaded area) blocks icv testosterone self-administration Asterisks indicate significant preference for the active nose-poke. Redrawn from [131].

antinociception in mice [31], rats [133] or monkeys [117]. In fact, nandrolone pre-exposure inhibited tolerance to morphine-induced antinociception and blunted morphineinduced CPP in mice [31] and rats [133]. Similarly, pretreatment with AAS blunted morphine-stimulated Fos expression in the dorsomedial caudate putamen [73]. AAS effects on opiate withdrawal are variable. While Negus et al. [117] observed no effect of AAS on naloxone-precipitated morphine withdrawal in monkeys, Celerier et al. [31] reported that nandrolone pretreatment enhanced withdrawal symptoms to naloxone in morphine-dependent mice.

AAS modify the levels of opioid peptides and their receptors in the brain. Steroids increase $\beta$-endorphin levels in the VTA [84] and paraventricular thalamus (PVT) [73] and appear to enhance $\beta$-endorphin fiber staining in BST and PVT [111]. However, the number of B-endorphin cells is reduced in ARC [111]. Opioid receptors also show regional variations in response to AAS. Nandrolone increases $\mathrm{mu}$, delta and kappa receptor binding in the hypothalamus, striatum and midbrain periaqueductal gray [82]. However, nandrolone reduces levels of dynorphin b in Acb [83], and attenuates delta receptors in cultured neuronal cells in vitro [129]. The steroid-induced increase in kappa receptors is consistent with the attenuated hypothermic response to morphine and the enhanced antinociceptive effects of U50,488 [161]. However, the reinforcing effects of opioids are thought to be mediated principally by $\mathrm{mu}$ and delta receptors [161]. Region-specific up- or down-regulation of $\beta$-endorphin and mu and delta receptors could account 
for the contrasting effects of AAS on opioid responses reported in experimental studies.

There is also a precedent for an interaction of androgens and opioids in humans $[9,169,172]$. In 2002, Arvary and Pope suggested that AAS could act as a gateway drug to opioid dependence [9]. In a survey of 223 men entering a drug treatment program, AAS use was considerably higher $(25 \%)$ among opioid users, compared with men using other drugs $(5 \%)$ [91]. Co-abuse of AAS and opiates has a certain logic. Most AAS users also engage in high-intensity exercise to maximize anabolic gains. Through their analgesic actions, opioids enable the user to continue training despite muscle and joint pain from injury and overtraining. Accordingly, some AAS users take opioids. In particular, nalbuphine hydrochloride (Nubain) is popular among bodybuilders [183], and is associated with other substance misuse. In the clinical literature, naloxone has been used to treat AAS withdrawal in a bodybuilder [169], and AAS appear to interact with heroin in accidental drug overdose [172].

Androgens and opioids have similar status from a medico-legal standpoint. Both have legitimate medical uses, but both are also drugs of abuse [44,56]. Increasingly, steroids and opiates appear in the same legal cases. In January 2005, a businessman in Edmonton, Canada was arrested for importing a kilogram of opium, 12,600 tablets of stanozolol and 4650 tablets of nandrolone [14]. A Seattle man was sentenced in 2006 to 2.5 years in prison for distributing AAS and prescription opiates, including Oxycontin [76]. Early in 2007, the son of Philadelphia Eagles coach Andy Reid was arrested after police found syringes of heroin and testosterone in his car [151].

\section{The bottom line: what have we learned?}

From the experimental evidence accumulated thus far in studies of humans and animals, it appears that AAS have elements in common with other drugs of abuse. AAS can cause lasting changes in behavior that are consistent with drug dependence, at least in susceptible individuals. As defined by the National Academy of Science, drug dependence is characterized by loss of control over use, such that subjects continue to seek out the drug despite adverse consequences [37]. Other criteria to establish dependence in animal studies include tolerance, withdrawal and sensitization [96]. Thus far in our studies of hamsters, we have observed fatal overdose during testosterone self-administration and tolerance to the depressive effects of high-dose testosterone $[131,132]$. Tolerance and self-administration to the point of death suggest the potential for AAS dependence. Furthermore, AAS act on brain regions that control drug dependence. In the search to uncover mechanisms of AAS action, it is reasonable to expect that a variety of transmitter systems are involved. This reflects the varieties of behavioral changes that steroids induce. To further define the potential for androgen dependence, it will be important to determine the brain targets and cellular mechanisms for androgen reinforcement.

Nonetheless, it appears that androgen reinforcement is not comparable to that of cocaine or heroin. Instead, it is likely that steroid reinforcement is similar to that of other mild reinforcers, such as caffeine, nicotine, or benzodiazepines. Rats in an operant chamber respond vigorously for iv heroin [41] or cocaine [20,107]. In contrast, by oral [85,184], iv [185] or icv self-administration [11,50,51,185], rats and hamsters show only a modest preference for testosterone. Similar results have been observed for oral [46] and iv [134] corticosterone self-administration in rats at comparable doses. Many other mild reinforcers do not support substantial self-administration. Caffeine is not selfadministered iv [19]. While rats do self-administer diazepam and nicotine iv, rates of operant responding are modest $[107,116]$. Moreover, rats prefer cocaine over nicotine in a two-lever choice test [107]. Although nicotine and benzodiazepines are mild reinforcers, it can be remarkably difficult for many habitual users to quit. AAS may have similar effects.

Ultimately, AAS abuse is a human problem. Data from animal studies suggest the potential for androgen dependence in humans, but this demands further clinical investigation. Current information on the prevalence and patterns of AAS use in humans is essential. Unfortunately, AAS use in humans is a moving target, with new steroids, new stacks and a ready supply of new users to test them out on. However, as our understanding from laboratory animal experiments converges with insight from human studies, we can create a more detailed picture of the problems and risks of AAS abuse.

\section{Acknowledgments}

Many people have contributed to this work. In particular, I thank Cortney L. Ballard, Lucy Chu, Luke R. Johnson, Anita Nagypal, Kelly D. Peters, Satoru Sato, and Jennifer L. Triemstra. This research supported by NIH RO1-DA12843.

\section{References}

[1] ACSM, Position Statement: Senate Hearing on the Abuse of Anabolic Steroids and Their Precursors by Adolescent Athletes. American College of Sports Medicine (2006).

[2] J.L. Aikey, J.G. Nyby, D.M. Anmuth, P.J. James, Testosterone rapidly reduces anxiety in male house mice (Mus musculus), Horm. Behav. 42 (2002) 448-460.

[3] G.M. Alexander, M.G. Packard, M. Hines, Testosterone has rewarding affective properties in male rats: implications for the biological basis of sexual motivation, Behav. Neurosci. 108 (1994) 424-428.

[4] L. Alzado, I'm sick and I'm scared, Sports Illus. 27 (1991) 21-24.

[5] R.A. Anderson, J. Bancroft, F.C. Wu, The effects of exogenous testosterone on sexuality and mood of normal men, J. Clin. Endocrinol. Metab. 75 (1992) 1503-1507.

[6] E. Ansari, J.R. Cook, Profound hypothermia mimicking a Brugada type ECG, J. Electrocardiol. 36 (2003) 257-260. 
[7] M.T. Arnedo, A. Salvador, S. Martinez-Sanchis, E. Gonzalez-Bono, Rewarding properties of testosterone in intact male mice: a pilot study, Pharmacol. Biochem. Behav. 65 (2000) 327-3233.

[8] M.T. Arnedo, A. Salvador, S. Martinez-Sanchis, O. Pellicer, Similar rewarding effects of testosterone in mice rated as short and long attack latency individuals, Addict. Biol. 7 (2002) 373-379.

[9] D. Arvary, H.G. Pope Jr., Anabolic steroids: a possible gateway to opioid dependence, N. Engl. J. Med. 342 (2000) 1532-1533.

[10] H. Baier, G. Biro, K.F. Weinger, Serum levels of FSH, LH and testosterone in human males, Horm. Metab. Res. 6 (1974) 514-516.

[11] C.L. Ballard, R.I. Wood, Male hamsters self-administer commonlyabused androgens, Behav. Neurosci. 119 (2005) 752-758.

[12] A. Bartke, Male hamster reproductive endocrinology, in: H.I. Siegel (Ed.), The Hamster: Reproduction and Behavior, Plenum Press, NY, 1985, pp. 74-98.

[13] C. Birgner, A.M. Kindlundh-Hogberg, F. Nyberg, L. Bergstrom, Altered extracellular levels of DOPAC and HVA in the rat nucleus accumbens shell in response to sub-chronic nandrolone administration and a subsequent amphetamine challenge, Neurosci. Lett. 412 (2007) 168-172T.

[14] R. Blais, Four years for city businessman, Edmonton Sun Sports, 12/11/2006. Available from: http://www.edmontonsun.com/Sports/ Eskimos/2006/12/11/2737390.html.

[15] C. Bodo, E.F. Rissman, New roles for estrogen receptor beta in behavior and neuroendocrinology, Front. Neuroendocrinol. 27 (2) (2006) 217-32A.

[16] G. Bolding, L. Sherr, J. Elford, Use of anabolic steroids and associated health risks among gay men attending London gyms, Addiction 97 (2002) 195-203.

[17] G. Bonci, P. Bernardi, N. Grillner, N.B. Mercuri, The dopaminecontaining neuron: maestro or simple musician in the orchestra of addiction? Trends Pharmacol. Sci. 24 (2003) 172-177.

[18] A.J. Bond, P.Y. Choi, H.G. Pope Jr., Assessment of attentional bias and mood in users and non-users of anabolic-androgenic steroids, Drug Alcohol Depend. 37 (1995) 241-245.

[19] V. Boonyaratanakornkit, D.P. Edwards, Receptor mechanisms mediating non-genomic actions of sex steroids, Semin. Reprod. Med. 25 (2007) 139-153.

[20] R.J. Briscoe, S.A. Vanechek, M. Vallett, T.J. Baird, F.A. Holloway, D.V. Gauvin, Reinforcing effects of caffeine, ephedrine, and their binary combination in rats, Pharmacol. Biochem. Behav. 60 (1998) 685-693.

[21] F.H. Bronson, C.M. Matherne, Exposure to anabolic-androgenic steroids shortens life span of male mice, Med. Sci. Sports Exerc. 29 (1997) 615-619.

[22] K.J. Brower, Anabolic steroid abuse and dependence, Curr. Psychiatry Rep. 4 (2002) 377-380.

[23] K.J. Brower, F.C. Blow, T.P. Beresford, C. Fuelling, Anabolicandrogenic steroid dependence, J. Clin. Psychiatry 50 (1989) 31-33.

[24] K.J. Brower, F.C. Blow, G.A. Eliopulos, T.P. Beresford, Anabolic androgenic steroids and suicide, Am. J. Psychiatry 146 (1989) 1075.

[25] K.J. Brower, F.C. Blow, J.P. Young, E.M. Hill, Symptoms and correlates of anabolic-androgenic steroid dependence, Br. J. Addict. 86 (1991) 759-768.

[26] K.J. Brower, D.H. Catlin, F.C. Blow, G.A. Eliopulos, T.P. Beresford, Clinical assessment and urine testing for anabolicandrogenic steroid abuse and dependence, Am. J. Drug Alcohol Abuse 17 (1991) 161-171.

[27] K.J. Brower, G.A. Eliopulos, F.C. Blow, D.H. Catlin, T.P. Beresford, Evidence for physical and psychological dependence on anabolic androgenic steroids in eight weight lifters, Am. J. Psychiatry 147 (1990) 510-512.

[28] C.S. Carter, Female sexual behavior, in: H.I. Siegel (Ed.), The Hamster: Reproduction and Behavior, Plenum Press, NY, 1985, pp. 173-190.

[29] F. Catalina, L. Milewich, W. Frawley, V. Kumar, M. Bennett, Decrease of core body temperature in mice by dehydroepiandrosterone, Exp. Biol. Med. 227 (2002) 382-388.
[30] D.H. Catlin, T.H. Murray, Performance-enhancing drugs, fair competition, and Olympic sport, JAMA 276 (1996) 231-237.

[31] E. Celerier, M.T. Yazdi, A. Castane, S. Ghozland, F. Nyberg, R. Maldonado, Effects of nandrolone on acute morphine responses, tolerance and dependence in mice, Eur. J. Pharmacol. 465 (2003) 6981.

[32] F. Celotti, P. Negri-Cesi, A. Poletti, Steroid metabolism in the mammalian brain: 5alpha-reduction and aromatization, Brain Res. Bull. 44 (1997) 365-375.

[33] P.Y. Choi, H.G. Pope Jr., Violence toward women and illicit androgenic-anabolic steroid use, Ann. Clin. Psychiatry 6 (1994) 2125.

[34] T.J. Cicero, L.H. O'Connor, Abuse liability of anabolic steroids and their possible role in the abuse of alcohol, morphine, and other substances, in: G.C. Lin, L. Erinoff (Eds.), Anabolic Steroid Abuse, NIDA Research Monograph 102, 1990, pp. 1-28.

[35] A.S. Clark, B.A. Costine, B.L. Jones, M.C. Kelton-Rehkopf, S.H Meerts, L.L. Nutbrown-Greene, C.A. Penatti, D.M. Porter, P. Yang, L.P. Henderson, Sex- and age-specific effects of anabolic androgenic steroids on reproductive behaviors and on GABAergic transmission in neuroendocrine control regions, Brain Res. 1126 (2006) 122-138.

[36] J.H. Clark, W.T. Schrader, B.W. O'Malley, Mechanisms of action of steroid hormones, in: J.L. Wilson, D.W. Foster (Eds.), William's Textbook of Endocrinology, eighth ed., WB Saunders Co, Philadelphia, 1992, pp. 35-90.

[37] Committee on Opportunities in Drug Addiction Research, Division of Neuroscience and Behavioral Health, Institute of Medicine, Pathways of Addiction: Opportunities in Drug Addiction Research, National Academy Press, Washington, DC, 1996.

[38] G.N. Conacher, D.G. Workman, Violent crime possibly associated with anabolic steroid use, Am. J. Psychiatry 146 (1989) 679.

[39] T.M. Creagh, A. Rubin, D.J. Evans, Hepatic tumours induced by anabolic steroids in an athlete, J. Clin. Pathol. 41 (1988) 441-443.

[40] M. Dadmarz, W.H. Vogel, Individual self-administration of nicotine by rats, Pharmacol. Biochem. Behav. 76 (2003) 425-432.

[41] S. Dai, W.A. Corrigall, K.M. Coen, H. Kalant, Heroin selfadministration by rats: influence of dose and physical dependence, Pharmacol. Biochem. Behav. 32 (1989) 1009-1015.

[42] R.C. Daly, T.P. Su, P.J. Schmidt, D. Pickar, D.L. Murphy, D.R. Rubinow, Cerebrospinal fluid and behavioral changes after methyltestosterone administration: preliminary findings, Arch. Gen. Psychiatry 58 (2001) 172-177.

[43] V. David, T.P. Durkin, P. Cazala, Differential effects of the dopamine D2/D3 receptor antagonist sulpiride on self-administration of morphine into the ventral tegmental area or the nucleus accumbens, Psychopharmacology 160 (2002) 307-317.

[44] DEA, 21 USC Sec. 812 01/22/02. TITLE 21-Food and Drugs Chapter 13-Drug abuse prevention and control subchapter Icontrol and enforcement Part B-Authority To Control; Standards and Schedules. Sec. 812. Schedules of controlled substances, 2002.

[45] R. DeBeun, E. Jansen, J.L. Slangen, N. Van De Poll, Testosterone as appetitive and discriminative stimulus in rats: sex- and dosedependent effects, Physiol. Behav. 52 (1992) 629-634.

[46] V. DeRoche, P. Vincenzo, P. Piazza, J.-M. Deminiere, M. Le Moal, H. Simon, Rats orally self-administer corticosterone, Brain Res. 622 (1993) 315-320.

[47] G. Di Chiara, V. Bassareo, S. Fenu, M.A. De Luca, L. Spina, C. Cadoni, E. Acquas, E. Carboni, V. Valentini, D. Lecca, Dopamine and drug addiction: the nucleus accumbens shell connection, Neuropharmacology 47 (Suppl 1) (2004) 227-241.

[48] R.D. Dickerman, W.J. McConathy, N.Y. Zachariah, Testosterone, sex hormone-binding globulin, lipoproteins, and vascular disease risk, J. Cardiovasc. Risk 4 (1997) 363-366.

[49] R.D. Dickerman, F. Schaller, I. Prather, W.J. McConathy, Sudden cardiac death in a 20-year-old bodybuilder using anabolic steroids, Cardiology 86 (1995) 172-173. 
[50] A.N. DiMeo, R.I. Wood, Circulating androgens increase sensitivity to exogenous testosterone self-administration in male hamsters, Pharmacol. Biochem. Behav. 79 (2004) 383-389.

[51] A.N. DiMeo, R.I. Wood, Self-administration of estrogen and dihydrotestosterone in male hamsters, Horm. Behav. 49 (2006) 529-536.

[52] A.N. DiMeo, R.I. Wood, Anabolic steroids activate Fos in forebrain and brainstem, Psychoneuroendocrinology 31 (2006) 237-249.

[53] M. DiPasquale, Anabolic steroids, in: R.E. Tarter, R.T. Ammerman, P.J. Ott (Eds.), Handbook of Substance Abuse, Plenum Press, NY, 1998, pp. 547-565.

[54] M.J. Diver, Analytical and physiological factors affecting the interpretation of serum testosterone concentration in men, Ann. Clin. Biochem. 43 (2006) 3-12.

[55] L.L. DonCarlos, S. Sarkey, B. Lorenz, I. Azcoitia, D. GarciaOvejero, C. Huppenbauer, L.M. Garcia-Segura, Novel cellular phenotypes and subcellular sites for androgen action in the forebrain, Neuroscience 138 (2006) 801-807.

[56] L. Dykstra, Opioid analgesics, Handb. Exp. Pharmacol. 118 (1996) 197-232.

[57] D.K. Eaton, L. Kann, S. Kinchen, J. Ross, J. Hawkins, W.A Harris, R. Lowry, T. McManus, D. Chyen, S. Shanklin, C. Lim, J.A. Grunbaum, H. Wechsle H, Youth Risk Behavior SurveillanceUnited States, 2005, Morbidity \& Mortality Weekly Report, 55(SS5) (2006) 1-108.

[58] S.F. Farrell, M.Y. McGinnis, Long-term effects of pubertal anabolic-androgenic steroid exposure on reproductive and aggressive behaviors in male rats, Horm. Behav. 46 (2004) 193-203.

[59] M.I. Fingerhood, J.T. Sullivan, M. Testa, D.R. Jasinski, Abuse liability of testosterone, J. Psychopharmacol. 11 (1997) 59-63.

[60] G. Fink, B.E. Sumner, J.K. McQueen, H. Wilson, R. Rosie, Sex steroid control of mood, mental state and memory, Clin. Exp. Pharmacol. Physiol. 25 (1998) 764-775.

[61] K.E. Friedl, Reappraisal of the health risks associated with the use of high doses of oral and injectable androgenic steroids, in: G.C. Lin, L. Erinoff (Eds.), Anabolic Steroid Abuse, NIDA Research Monograph 102, 1990, pp. 142-177.

[62] C.A. Frye, M.E. Rhodes, R. Rosellini, B. Svare, The nucleus accumbens as a site of action for rewarding properties of testosterone and its 5alpha-reduced metabolites, Pharmacol. Biochem. Behav. 74 (2002) 119-127.

[63] C.A. Frye, A.M. Seliga, Testosterone increases analgesia, anxiolysis, and cognitive performance of male rats, Cogn. Affect. Behav. Neurosci. 1 (2001) 371-381.

[64] J.R. Fuller, M.J. LaFountain, Performance-enhancing drugs in sport: a different form of drug abuse, Adolescence 22 (1987) 969-976.

[65] S. Gallaway, The Steroid Bible, Belle International Press, Sacramento, 1997.

[66] N. Galligani, A. Renck, S. Hansen, Personality profile of men using anabolic androgenic steroids, Horm. Behav. 30 (1996) 170-1755.

[67] J. Gobinet, N. Poujol, C. Sultan, Molecular action of androgens, Mol. Cell. Endocrinol. 198 (2002) 15-24.

[68] J.M. Grimes, R.H. Melloni Jr., Serotonin modulates offensive attack in adolescent anabolic steroid-treated hamsters, Pharmacol. Biochem. Behav. 73 (2002) 712-713.

[69] J.M. Grimes, R.H. Melloni Jr., Prolonged alterations in the serotonin neural system following the cessation of adolescent anabolic-androgenic steroid exposure in hamsters (Mesocricetus auratus), Behav. Neurosci. 120 (2006) 1242-1251.

[70] A.J. Gruber, H.G. Pope Jr., Psychiatric and medical effects of anabolic-androgenic steroid use in women, Psychother. Psychosom. 69 (2000) 19-26.

[71] D. Gwartney, Steroid addiction: fact or fallacy? Muscle Dev. (2005) 286-292.

[72] C.J. Hannan Jr, K.E. Friedl, A. Zold, T.M. Kettler, S.R. Plymate, Psychological and serum homovanillic acid changes in men administered androgenic steroids, Psychoneuroendocrinology 16 (1991) 335-343.
[73] R.E. Harlan, H.E. Brown, C.S. Lynch, D. D'Souza, M.M. Garcia, Androgenic-anabolic steroids blunt morphine-induced c-fos expression in the rat striatum: possible role of B-endorphin, Brain Res. 853 (2000) 99-104.

[74] R.J. Harrison, D.F. Connor, C. Nowak, K. Nash, R.H. Melloni Jr., Chronic anabolic-androgenic steroid treatment during adolescence increases anterior hypothalamic vasopressin and aggression in intact hamsters, Psychoneuroendocrinology 25 (2000) 317338.

[75] L.R. Hays, S. Littleton, V. Stillner, Anabolic steroid dependence, Am. J. Psychiatry 147 (1990) 122.

[76] Herald Staff, Marysville man sentenced as leader of drug ring, Seattle Herald, 4/28/06. Available from: http://www.heraldnet.com/ stories/06/04/28/100loc_b2steroids001.cfm.

[77] J. Hoberman, Testosterone Dreams: Rejuvenation, Aphrodisia, Doping, University of California Press, Berkeley, 2005.

[78] E.M. Hull, D.S. Lorrain, J. Du, L. Matuszewich, L.A. Lumley, S.K. Putnam, J. Moses, Hormone-neurotransmitter interactions in the control of sexual behavior, Behav. Brain Res. 105 (1999) 105116.

[79] E.M. Hull, R.I. Wood, K.E. McKenna, Male sexual behavior, in: J.D. Neill (Ed.), The Physiology of Reproduction, third ed., Raven Press, NY, 2006, pp. 1729-1824.

[80] D.M. Hutcheson, J.A. Parkinson, T.W. Robbins, B.J. Everitt, The effects of nucleus accumbens core and shell lesions on intravenous heroin self-administration and the acquisition of drug-seeking behaviour under a second-order schedule of heroin reinforcement, Psychopharmacology 153 (2001) 464-472.

[81] T. Inoue, J. Akahira, T. Suzuki, A.D. Darnel, C. Kaneko, K. Takahashi, M. Hatori, R. Shirane, T. Kumabe, Y. Kurokawa, S. Satomi, H. Sasano, Progesterone production and actions in the human central nervous system and neurogenic tumors, J. Clin. Endocrinol. Metab. 87 (2002) 5325-5331.

[82] P. Johansson, M. Hallberg, A. Kindlundh, F. Nyberg, The effect on opioid peptides in the rat brain, after chronic treatment with the anabolic androgenic steroid, nandrolone decanoate, Brain Res. Bull. 51 (2000) 413-418.

[83] P. Johansson, A. Lindqvist, F. Nyberg, C. Fahlke, Anabolic androgenic steroids affects alcohol intake, defensive behaviors and brain opioid peptides in the rat, Pharmacol. Biochem. Behav. 67 (2000) 271-279.

[84] P. Johansson, A. Ray, Q. Zhou, W. Huang, K. Karlsson, F. Nyberg, Anabolic androgenic steroids increase B-endorphin levels in the ventral tegmental area in the male rat brain, Neurosci. Res. 27 (1997) $185-189$.

[85] L.R. Johnson, R.I. Wood, Oral testosterone self-administration in male hamsters, Neuroendocrinology 73 (2001) 285-292.

[86] L.D. Johnston, P.M. O'Malley, J.G. Bachman, Monitoring the Future national survey results on drug use, 1975-2002. Volume I: Secondary school students (NIH Publication No. 03-5375), National Institute on Drug Abuse, Bethesda, MD, 2003.

[87] J.C. Jorge, K.T. Velazquez, D.L. Ramos-Ortolaza, I. Lorenzini, J. Marrero, C.S. Maldonado-Vlaar, A testosterone metabolite is rewarding to ovariectomized female rats, Behav. Neurosci. 119 (2005) 1222-12226.

[88] J.C. Jorge-Rivera, K.L. McIntyre, L.P. Henderson, Anabolic steroids induce region- and subunit-specific rapid modulation of GABA(A) receptor-mediated currents in the rat forebrain, J. Neurophysiol. 83 (2000) 3299-3309.

[89] R.C. Kammerer, Drug testing and anabolic steroids, in: C.E. Yesalis (Ed.), Anabolic Steroids in Sport and Exercise, Human Kinetics, Champaign, IL, 2000, pp. 415-459.

[90] G. Kanayama, M. Boynes, J.I. Hudson, A.E. Field, H.G. Pope Jr., Anabolic steroid abuse among teenage girls: an illusory problem? Drug Alcohol Depend. 88 (2007) 156-162.

[91] G. Kanayama, G.H. Cohane, R.D. Weiss, H.G. Pope Jr., Past anabolic-androgenic steroid use among men admitted for substance 
abuse treatment: an underrecognized problem? J. Clin. Psychiatry 64 (2003) 156-160.

[92] S.B. Karch, Karch's Pathology of Drug Abuse, third ed., CRC Press, Boca Raton, 2002.

[93] K.B. Kashkin, H.D. Kleber, Hooked on hormones? An anabolic steroid addiction hypothesis, JAMA 262 (1989) 3166-3170.

[94] A.M. Kindlundh, J. Lindblom, L. Bergstrom, F. Nyberg, The anabolic-androgenic steroid nandrolone induces alterations in the density of serotonergic 5HT1B and 5HT2 receptors in the male rat brain, Neuroscience 119 (2003) 113-120.

[95] B.E. King, M.G. Packard, G.M. Alexander, Affective properties of intra-medial preoptic area injections of testosterone in male rats, Neurosci. Lett. 269 (1999) 149-152.

[96] G.F. Koob, E.J. Nestler, The neurobiology of drug addiction, J. Neuropsychiatry Clin. Neurosci. 9 (1997) 482-497.

[97] M.F. Kritzer, Selective colocalization of immunoreactivity for intracellular gonadal hormone receptors and tyrosine hydroxylase in the ventral tegmental area, substantia nigra, and retrorubral fields in the rat, J. Comp. Neurol. 379 (1997) 247-260

[98] E.M. Kouri, S.E. Lukas, H.G. Pope Jr., P. S Oliva, Increased aggressive responding in male volunteers following the administration of gradually increasing doses of testosterone cypionate, Drug Alcohol Depend. 40 (1995) 73-79.

[99] S. Kurling, A. Kankaanpaa, S. Ellermaa, T. Karila, T. Seppala, The effect of sub-chronic nandrolone decanoate treatment on dopaminergic and serotonergic neuronal systems in the brains of rats, Brain Res. 1044 (2005) 67-75.

[100] M.G. LeSage, D.E. Keyler, G. Collins, P.R. Pentel, Effects of continuous nicotine infusion on nicotine self-administration in rats: relationship between continuously infused and self-administered nicotine doses and serum concentrations, Psychopharmacology 170 (2003) 278-286.

[101] A.I. Leshner, Anabolic steroid abuse, NIDA Research Report Series, NIH Publication 00-3721, 2000.

[102] A.S. Lindqvist, P. Johansson-Steensland, F. Nyberg, C. Fahlke, Anabolic androgenic steroid affects competitive behaviour, behavioural response to ethanol and brain serotonin levels, Behav. Brain Res. 133 (2002) 21-29.

[103] R.D. Lisk, The estrous cycle, in: H.I. Siegel (Ed.), The Hamster: Reproduction and Behavior, Plenum Press, NY, 1985, pp. 23-52.

[104] J.A. Lombardo, Anabolic-androgenic steroids, in: G.C. Lin, L. Erinoff (Eds.), Anabolic Steroid Abuse, NIDA Research Monograph 102,1990 , pp. 60-73.

[105] G. Lukas, S.D. Brindle, P. Greengard, The route of absorption of intraperitoneally administered compounds, J. Pharm. Exp. Ther. 178 (1971) 562-566.

[106] D.A. Malone, J.M. Sorboro, Anabolic-androgenic steroids, in: N.S. Miller (Ed.), Principles of Addiction Medicine, American Society of Addiction Medicine, Section II, Chapter 9, 1994.

[107] A.M. Manzardo, L. Stein, J.D. Belluzzi, Rats prefer cocaine over nicotine in a two-lever self-administration choice test, Brain Res. 924 (2002) 10-19.

[108] B.J. Maron, J. Shirani, L.C. Poliac, R. Mathenge, W.C. Roberts, F.O. Mueller, Sudden death in young competitive athletes. Clinical, demographic, and pathological profiles, JAMA 276 (1996) 199-204.

[109] M.Y. McGinnis, Anabolic androgenic steroids and aggression: studies using animal models, Ann. NY Acad. Sci. 1036 (2004) 399415.

[110] R.H. Melloni Jr., D.F. Connor, P.T. Hang, R.J. Harrison, C.F. Ferris, Anabolic-androgenic steroid exposure during adolescence and aggressive behavior in golden hamsters, Physiol. Behav. 61 (1997) 359-364.

[111] C.S. Menard, T.J. Hebert, G.P. Dohanich, R.E. Harlan, Androgenic-anabolic steroids modify beta-endorphin immunoreactivity in the rat brain, Brain Res. 669 (1995) 255-262.
[112] P.G. Mermelstein, J.B. Becker, D.J. Surmeier, Estradiol reduces calcium currents in rat neostriatal neurons via a membrane receptor, J. Neurosci. 16 (1996) 595-604.

[113] S.J. Midgley, N. Heather, J.B. Davies, Levels of aggression among a group of anabolic-androgenic steroid users, Med. Sci. Law 41 (2001) 309-314.

[114] E.P. Monaghan, S.E. Glickman, Hormones and aggressive behavior, in: J.B. Becker, S.M. Breedlove, D. Crews (Eds.), Behavioral Endocrinology, MIT Press, MA, 1992, pp. 261-286.

[115] H.B. Moss, G.L. Panzak, R.E. Tarter, Sexual functioning of male anabolic steroid users, Arch. Sex. Behav. 22 (1993) 1-12.

[116] T. Naruse, T. Asami, Intravenous self-administration of diazepam in rats, Eur. J. Pharmacol. 135 (1987) 365-373.

[117] S.S. Negus, H.G. Pope Jr., G. Kanayama, J.D. Wines Jr., B.D Fischer, Lack of evidence for opioid tolerance or dependence in rhesus monkeys following high-dose anabolic-androgenic steroid administration, Psychoneuroendocrinology 26 (2001) 789-796.

[118] NHANES. Available from: http://www.cdc.gov/od/oc/media/press$\mathrm{rel} / \mathrm{r} 041027 . \mathrm{htm}$, accessed 5/13/07.

[119] NIDA Research Reports. Available from: http://www.nida.nih.gov/ ResearchReports/Nicotine/nicotine2.html\#what, accessed 10/20/04.

[120] R.G. Noble, P.B. Alsum, Hormone dependent sex dimorphisms in the golden hamster (Mesocricetus auratus), Physiol. Behav. 14 (1975) $567-574$.

[121] D.B. O'Connor, J. Archer, F.C. Wu, Effects of testosterone on mood, aggression, and sexual behavior in young men: a doubleblind, placebo-controlled, cross-over study, J. Clin. Endocrinol. Metab. 89 (2004) 2837-2845.

[122] C.C. Oliva, R.K. Middleton, Anabolic steroid-induced psychiatric reactions, DICP 24 (1990) 388.

[123] M.G. Packard, A.H. Cornell, G.M. Alexander, Rewarding affective properties of intra-nucleus accumbens injections of testosterone, Behav. Neurosci. 111 (1997) 219-224.

[124] M.G. Packard, J.P. Schroeder, G.M. Alexander, Expression of testosterone conditioned place preference is blocked by peripheral or intra-accumbens injection of $\alpha$-flupenthixol, Horm. Behav. 34 (1998) $39-47$.

[125] T.R. Pak, W.C. Chung, T.D. Lund, L.R. Hinds, C.M. Clay, R.J. Handa, The androgen metabolite, 5alpha-androstane-3beta, 17betadiol, is a potent modulator of estrogen receptor-beta1-mediated gene transcription in neuronal cells, Endocrinology 146 (2005) 147-155.

[126] A.C. Parrott, P.Y. Choi, M. Davies, Anabolic steroid use by amateur athletes: effects upon psychological mood states, J. Sports Med. Phys. Fitness 34 (1994) 292-298.

[127] M. Parssinen, U. Kujala, E. Vartiainen, S. Sarna, T. Seppala, Increased premature mortality of competitive powerlifters suspected to have used anabolic agents, Int. J. Sports Med. 21 (2000) 225-227.

[128] M. Parssinen, T. Seppala, Steroid use and long-term health risks in former athletes, Sports Med. 32 (2002) 83-94.

[129] A. Pasquariello, R. Di Toro, F. Nyberg, S. Spampinato, Downregulation of delta opioid receptor mRNA by an anabolic steroid in neuronal hybrid cells, Neuroreport 11 (2000) 863-867.

[130] P.J. Perry, E.C. Kutscher, B.C. Lund, W.R. Yates, T.L. Holman, L. Demers, Measures of aggression and mood changes in male weightlifters with and without androgenic anabolic steroid use, J. Forensic Sci. 48 (2003) 646-651.

[131] K.D. Peters, R.I. Wood, Androgen overdose: behavioral and physiologic effects of testosterone infusion, Neuroscience 130 (2004) 971-981.

[132] K.D. Peters, R.I. Wood, Anabolic-androgenic steroid addiction involves androgen and opioid receptors, Program No. 997.6. 2004 Abstract Viewer/Itinerary Planner, Society for Neuroscience, Washington, DC (Online).

[133] T. Philipova, T. Ivanova, E. Pavlova, L. Kasakov, M. Vlaskovska, Nandrolone modulates the non-opioid and opioid analgesia and tolerance/dependence: role of sexual dimorphism, Arch. Physiol. Biochem. 111 (2003) 429-436. 
[134] P. Piazza, V. DeRoche, J.-M. Deminiere, S. Maccari, M. Le Moal, H. Simon, Corticosterone in the range of stressinduced levels possesses reinforcing properties: implications for sensation-seeking behaviors, PNAS 90 (1993) 11738 11742.

[135] H.G. Pope Jr., A.J. Gruber, B. Mangweth, B. Bureau, C. deCol, R. Jouvent, Body image perception among men in three countries, Am. J. Psychiatry 157 (2001) 1297-12301.

[136] H.G. Pope Jr., D.L. Katz, Bodybuilder's psychosis, Lancet 1 (1987) 863.

[137] H.G. Pope Jr., D.L. Katz, Affective and psychotic symptoms associated with anabolic steroid use, Am. J. Psychiatry 145 (1988) 487-490.

[138] H.G. Pope Jr., D.L. Katz, Homicide and near-homicide by anabolic steroid users, J. Clin. Psychiatry 51 (1990) 28-31.

[139] H.G. Pope Jr., D.L. Katz, Psychiatric and medical effects of anabolic-androgenic steroid use. A controlled study of 160 athletes, Arch. Gen. Psychiatry 51 (1994) 375-382.

[140] H.G. Pope Jr., E.M. Kouri, J.I. Hudson, Effects of supraphysiologic doses of testosterone on mood and aggression in normal men: a randomized controlled trial, Arch. Gen. Psychiatry 57 (2000) 133140.

[141] H.G. Pope Jr, E.M. Kouri EM, K.F. Powell, C. Campbell, D.L. Katz, Anabolic-androgenic steroid use among 133 prisoners, Comp. Psychiatry 37 (1996) 322-327.

[142] L.A. Ricci, K. Rasakham, J.M. Grimes, R.H. Melloni Jr., Seotonin$1 \mathrm{~A}$ receptor activity and expression modulate adolescent anabolic/ androgenic steroid-induced aggression in hamsters, Pharmacol. Biochem. Behav. 85 (2006) 1-11.

[143] Z.A. Rodd-Henricks, D.L. McKinzie, T.K. Li, J.M. Murphy, W.J. McBride, Cocaine is self-administered into the shell but not the core of the nucleus accumbens of Wistar rats, J. Pharmacol. Exp. Ther. 303 (2002) 1216-1226.

[144] R.A. Rosellini, B.B. Svare, M.E. Rhodes, C.A. Frye, The testosterone metabolite and neurosteroid 3alpha-androstanediol may mediate the effects of testosterone on conditioned place preference, Brain Res. Brain Res. Rev. 37 (2001) 162-171.

[145] M.E. Roth, K.P. Cosgrove, M.E. Carroll, Sex differences in the vulnerability to drug abuse: a review of preclinical studies, Neurosci. Biobehav. Rev. 28 (2004) 533-546.

[146] T. Saartok, E. Dahlberg, J.A. Gustafsson, Relative binding affinity of anabolic-androgenic steroids: comparison of the binding to the androgen receptors in skeletal muscle and in prostate, as well as to sex hormone-binding globulin, Endocrinology 114 (1984) 21002106.

[147] J.D. Salamone, M. Correa, Motivational views of reinforcement: implications for understanding the behavioral functions of nucleus accumbens dopamine, Behav. Brain Res. 137 (2002) 325.

[148] SAMHSA/OAS, 1994, National Household Survey on Drug Abuse, Main Findings 1994, DHHS Publication No (SMA) 963085,1996

[149] SAMHSA/OAS, Results from the 2004 National Survey on Drug Use and Health: National Findings, NSDUH Series H-28, DHHS Publication No. SMA 05-4062, 2005.

[150] S.M. Sato, J. Johanson, C.L. Jordan, R.I. Wood, Androgen self-administration in Tfm rats, Tenth Annual Meeting of the Society for Behavioral Neuroendocrinology, 2006, P83.

[151] M.A. Schaefer, Garrett Reid, 23, has been charged, The Philadelphia Inquirer, 2/16/07, p. B02.

[152] P. Schnur, Acute morphine dependence in the hamster, Pharmacol. Biochem. Behav. 38 (1991) 711-713.

[153] P. Schnur, D. Hang, Naloxone reversal of morphine elicited hyperactivity, Life Sci. 40 (1987) 329-333.

[154] P. Schnur, V. Raigoza, Evidence for an underlying opponent process during morphine elicited hyperactivity in the hamster, Life Sci. 38 (1986) 1323-1329.
[155] J.P. Schroeder, M.G. Packard, Role of dopamine receptor subtypes in the acquisition of a testosterone conditioned place preference in rats, Neurosci. Lett. 282 (2000) 17-20.

[156] H.M. Schulte, M.J. Hall, M. Boyer, Domestic violence associated with anabolic steroid abuse, Am. J. Psychiatry 150 (1993) 348.

[157] P.J. Shugrue, M.V. Lane, I. Merchenthaler, Comparative distribution of estrogen receptor-alpha and -beta mRNA in the rat central nervous system, J. Comp. Neurol. 388 (1997) 507-525.

[158] H.I. Siegel, Male sexual behavior, in: H.I. Siegel (Ed.), The Hamster: Reproduction and Behavior, Plenum Press, NY, 1985, pp. 191-206.

[159] R.B. Simerly, Hormonal regulation of limbic and hypothalamic pathways, in: P.E. Micevych, R.P. HammerJr. (Eds.), Neurobiological Effects of Sex Steroid Hormones, Cambridge University Press, Cambridge, UK, 1995, pp. 85-116.

[160] R.B. Simerly, C. Chang, M. Muramatsu, L.W. Swanson, Distribution of androgen and estrogen receptor mRNA-containing cells in the rat brain: an in situ hybridization study, J. Comp. Neurol. 294 (1990) 76-95.

[161] E.C. Stoffel, C.M. Ulibarri, J.E. Folk, K.C. Rice, R.M. Craft, Gonadal hormone modulation of mu, kappa, and delta opioid antinociception in male and female rats, J. Pain 6 (2005) 261-274.

[162] B. Stoffel-Wagner, Neurosteroid biosynthesis in the human brain and its clinical implications, Ann. NY Acad. Sci. 1007 (2003) 64-78.

[163] T.P. Su, M. Pagliaro, P.J. Schmidt, D. Pickar, O. Wolkowitz, D.R. Rubinow, Neuropsychiatric effects of anabolic steroids in male normal volunteers, JAMA 269 (1993) 2760-2764.

[164] M.L. Sullivan, C.M. Martinez, E.J. Gallagher, Atrial fibrillation and anabolic steroids, J. Emerg. Med. 17 (1999) 851-857.

[165] J. Summers, Steroids 101, Anabolics.com, Inc, Aurora, CO, 2003.

[166] N.E. Tabori, L.S. Stewart, V. Znamensky, R.D. Romeo, S.E. Alves, B.S. McEwen, T.A. Milner, Ultrastructural evidence that androgen receptors are located at extranuclear sites in the rat hippocampal formation, Neuroscience 130 (2005) 151-163.

[167] W.N. Taylor, Synthetic anabolic-androgenic steroids: a plea for controlled substance status, Phys. Sports Med. 15 (1987) 140-150.

[168] W.N. Taylor, Anabolic Steroids and the Athlete, McFarland \& Co: Jefferson, NC, 2002.

[169] F. Tennant, D.L. Black, R.O. Voy, Anabolic steroid dependence with opioid-type features, N. Engl. J. Med. 319 (1988) 578.

[170] The Californian Mass Stack. Available from: www.freeanabolicsteroidsinfo.com/stacks\#20, accessed 10/24/05

[171] I. Thiblin, A. Finn, S.B. Ross, C. Stenfors, Increased dopaminergic and 5-hydroxytryptaminergic activities in male rat brain following long-term treatment with anabolic androgenic steroids, Br. J. Pharmacol. 126 (1999) 1301-1306.

[172] I. Thiblin, O. Lindquist, J. Rajs, Cause and manner of death among users of anabolic androgenic steroids, J. Forensic Sci. 45 (2000) 1623.

[173] I. Thiblin, T. Parlklo, Anabolic androgenic steroids and violence, Acta Psychiatr. Scand. Suppl. 412 (2002) 125-128.

[174] I. Thiblin, B. Runeson, J. Rajs, Anabolic androgenic steroids and suicide, Ann. Clin. Psychiatry 11 (1999) 223-231.

[175] R. Tricker, R. Casaburi, T.W. Storer, B. Clevenger, N. Berman, A. Shirazi, S. Bhasin, The effects of supraphysiological doses of testosterone on angry behavior in healthy eugonadal men-a clinical research center study, J. Clin. Endocrinol. Metab. 81 (1996) 37483754.

[176] J.L. Triemstra, R.I. Wood, Testosterone self-administration in female hamsters, Behav. Brain Res. 154 (2004) 221-229.

[177] J.L. Triemstra, R.I. Wood, Testosterone-induced dopamine release in nucleus accumbens of male Syrian hamsters, Horm. Behav. 48 (2005) 132.

[178] P. Van Eenoo, F.T. Delbeke, The prevalence of doping in Flanders in comparison to the prevalence of doping in international sports, Int. J. Sports Med. 24 (2003) 565-570.

[179] WADA Laboratory Committee, Reporting norandrosterone findings, WADA Technical Document-TD2004NA, 2004 
[180] WADA Laboratory Committee, Reporting and evaluation guidance for testosterone, epitestosterone, T/E ratio and other endogenous steroids, WADA Technical Document-TD2004EAAS, 2004.

[181] WADA, 2006 Adverse analytical findings reported by accredited laboratories. Available from: http://www.wada-ama.org.

[182] A.A. Walf, M.E. Rhodes, J.R. Meade, J.P. Harney, C.A. Frye, Estradiol-induced conditioned place preference may require actions at estrogen receptors in the nucleus accumbens, Neuropsychopharmacology 32 (2007) 522-530.

[183] J.D. Wines Jr., A.J. Gruber, H.G. Pope Jr., S.E. Lukas, Nalbuphine hydrochloride dependence in anabolic steroid users, Am. J. Addict. 8 (1999) 161-164.

[184] R.I. Wood, Oral testosterone self-administration in male hamsters: dose-response, voluntary exercise, and individual differences, Horm. Behav. 41 (2002) 247-258.

[185] R.I. Wood, L.R. Johnson, L. Chu, C.A. Schad, D.W. Self, Testosterone reward: intravenous and intracerebroventricular selfadministration, Psychopharmacology 171 (2004) 298-305.
[186] R.I. Wood, S.W. Newman, Sex differences in androgen receptor immunoreactivity in the brain of the Syrian hamster, J. Neurobiol. 39 (1999) 359-370.

[187] R.I. Wood, J.M. Swann, Neuronal integration of chemosensory and hormonal signals that control male sexual behavior, in: K. Wallen, J.S. Schneider (Eds.), Reproduction in Context, MIT Press, Cambridge, 1995, pp. 423-444.

[188] W.R. Yates, P.J. Perry, J. MacIndoe, T. Holman, V. Ellingrod, Psychosexual effects of three doses of testosterone cycling in normal men, Biol. Psychiatry 45 (1999) 254-260.

[189] C.E. Yesalis, Anabolic Steroids in Sport and Exercise, Human Kinetics, Champaign, IL, 2002.

[190] C.E. Yesalis, M.S. Bahrke, Anabolic androgenic steroids: incidence of use and health implications, President's Counc. Phys. Fitness Sports Res. Dig. 5 (2005) 1-8.

[191] C.E. Yesalis, N.J. Kennedy, A.N. Kopstein, M.S. Bahrke, Anabolic-androgenic steroid use in the United States, JAMA 270 (1993) $1217-1221$. 